\title{
Beschreibung neuer Ophiuriden und Bemerkungen zu bekannten.
}

\author{
Von \\ Gottlieb Marktanner-Turneretscher.
}

Mit zwei Tafeln (Nr. XII und XIII).

Auf Veranlassung des Herrn Custos Dr. E. von Marenzeller, welcher nach Vollendung der neuen Inventur und Ordnung der Echinodermensammlung des k. k. naturhistorischen Hofmuseums die Herausgabe eines Kataloges über dieselbe beabsichtigt, unternahm ich die Untersuchung der noch nicht bestimmten Vorräthe an Ophiuriden.

In der Folge dehnte ich jedoch meine Arbeit auch auf das übrige Material aus, insoferne es Anlass zu Bemerkungen und Ergänzungen bot, so dass man in dem Nachstehenden die Ergebnisse der Durchsicht der gesammten Sammlung der Ophiuriden finden wird. Die Sammlung ist nicht reich, sie enthält i 27 Species, darunter 8 neue, somit kaum 20 Procent der bekannten Arten (700). An typischen Exemplaren oder Originalexemplaren sind vorhanden: Ophioderma cinereum M.-Tr., Ophiolepis Tenorii M.-Tr., Ophiocoma Valenciae M.-Tr., Ophiothrix comata M.-Tr. und Ophiothrix violacea M.-Tr.

Als Grundlage der vorliegenden kleinen Publication diente Lyman's Report on the Ophiuroidea dredged by H. M. S. Challenger during the years I $873-1876$. Es wird bei allen besprochenen Arten auf dieses Werk und die dort citirte Litteratur hingewiesen und von letzterer stets nur jenes $\bar{W}$ erk namhaft gemacht, in welchem die betreffende Species zum ersten Male beschrieben wurde. Ferner wurden bei den sämmtlichen im Folgenden besprochenen Arten alle in der hiesigen Sammlung vertretenen Fundorte womöglich sammt Angabe des Sammlers oder der Bezugsquelle angeführt. ${ }^{\mathrm{I}}$ )

Hier sei es mir auch gestattet, zu erwähnen, dass die als Sammler öfters genannten Herren Dr. E. Billitzer, Schiffslieutenant Bobrik, Dr. Lippe und Dr. A. Wolf gelegentlich ihrer auf Schiffen der k. k. österreichischen Kriegsmarine gemachten Reisen die betreffenden Objecte sammelten.

Die Herstellung der beigegebenen Tafeln betreffend möchte ich nur anführen, dass ich die einzelnen Thiere mikrophotographisch aufnahm und die Negative auf gewöhnliches Albuminpapier copirte. Die einzelnen Copien wurden auf schwarzem Carton passend gruppirt aufgeklebt und hievon wurde noch eine Gesammtaufnahme gemacht,

I) In Klammern gestellte Namen bedeuten, dass die Exemplare nicht von dem Betreffenden selbst gesammelt wurden.

Annalen des k. k. naturhistorischen Hofmuseums, Bd. II, Heft 4, 1887. 
die als Matrize für das Lichtdruckcliché diente. Wenngleich viele der Abbildungen nicht tadellos sind, zum Theile darum, weil das vorliegende Material an Thieren ein beschränktes und deshalb eine günstige Auswahl nicht immer möglich war, so hoffe ich doch, mit dieser Art der Darstellung keinen Missgriff gethan zu haben. Allerdings können bei lithographischen Zeichnungen die in speciellen Fällen bemerkenswerthesten Einzelheiten besonders hervorgehoben werden, dafür aber bringt das photographische Bild nebst grösster Naturwahrheit den Gesammthabitus entschieden besser zum Ausdrucke.

Es erübrigt mir nur noch, an dieser Stelle dem Herrn Custos Dr. E. von Marenzeller meinen besten Dank für seine vielen mir gegebenen freundlichen Rathschläge zum Ausdrucke zu bringen.

\section{Verzeichniss der citirten Litteratur.}

(I) I776. O. F. Müller, Zoologiae Danicae Prodromus. Kopenhagen.

(2) I789. Ch. Abildga ard, Zoologia Danica, vol. III. Kopenhagen.

(3) I816. La marck, Hist. Anim. sans. Vertèbres, vol. II. Paris.

(4) I825. Th. Say, On the species of the Linnaean genus Asterias inhabit. the coast of the United States; Journ. Philad. Acad., vol. V.

(5) I839. Forbes, On the Asteriadae of the Irish Sea; Mem. Werner. Soc., vol. VIII. Edinburgh.

(6) I 842 . J. Müller und F. Troschel, System der Asteriden. Braunschweig.

(7) 1843. Forbes, On the Radiata of the eastern Mediterranean; Trans. Linn. Soc., vol. XIX. London.

(8) I85 I. O. Ayres, Ophiolepis robusta n. sp.; Proc. Bost. Soc. N. H., vol. IV.

(9) I852. Peters, Ueber neue Ophiuren aus Mossambique; Wiegm. Arch., Jahrg. I8, Band II.

(Iо) I854. Lütken, Bidrag til kundskab om slangestjernerne; Vidensk. Meddel. for 1854. Kopenhagen.

(I I) 1857. M. Sars, Bidrag til kundskaben om Middelhavets Littoral-Fauna; Nyt. Magaz. f. Naturvid., Band Io. Christiania.

(I2) I858. Lütken, Additamenta ad historiam Ophiuridarum, part. I; kongl. danske Vidensk. Selsk. Skrift, 5. Raekk, 5. Band. Kopenhagen.

(I3) I859. Id. part. II; ibid.

(I4) I860. Th. Lyman, Descriptions of new Ophiuridae; Proc. Bost. Soc. N. H., vol. VII.

(I5) I86I. Th. Lyman, Descriptions of new Ophiuridae; Proc. Bost. Soc. N. H., vol. VIII.

(I6) I862. C. Heller, Untersuchungen über die Litoralfauna des adriatischen Meeres; Sitzungsberichte der kais. Akademie der Wissenschaften, Band 46. Wien.

(1 7) I 865. Th. Lyman, Illustr. Catal. of the Mus. of Comp. Zool. at Harvard College, Nr. I. Cambridge.

(18) I866. A. Ljungman, Ophiuridea viventia huc usque cognita; Öfvers. af kongl. Vet. Akad. Förhandl. Stockholm.

(I9) I869. A. E. Verrill, On new and imperfectly known Echinoderms and Corals; Proc. Bost. Soc. N. H., vol. XII.

(20) I869. Lütken, Additamenta ad historiam Ophiuridarum, part. III; kongl. danske Vidensk. Selsk. Skrift, 5. Raekk, 8. Band.

(2i) I870. E. v. Martens, Die Ophiuriden des indischen Oceans; Archiv für Naturgeschichte, Band 36. Berlin.

(22) I872. Lütken, Ophiuridarum novar. vel minus cognit. descript. nonnullae; Overs. kongl. dansk. Vidensk. Selsk. Forh. i Aaret I872. Kopenhagen.

(23) 1874. Th. Lyman, Ophiuridae and Astrophytidae old and new; Bull. Mus. Comp. Zool., vol. III, pag. 10.

(24) 1875. E. v. Marenzeller, Revision adriatischer Seesterne; Verhandlungen der k. k. zool.-botan. Gesellschaft in Wien, Jahrg. I875.

(25) I878. M. Duncan, On some Ophiuroidea from the Korean Seas; Journ. Linn. Soc., vol. XIV.

(26) 1879. Th. Ly man, Ophiuridae and Astrophytidae of the „Challenger «-Expedition; Bull. Mus. Comp. Zool., vol. VI, part 2.

(27) I 879. H. Ludwig, Die Echinodermen des Mittelmeeres; Mittheilungen der zoologischen Station zu Neapel, Band I, Heft 4. Leipzig. 
(28) 1880. H. Ludwig, Echinodermen des rothen Meeres in: Kossman Robby, Zoologische Ergebnisse einer Reise im Küstengebiete des rothen Meeres, 2. Hälfte, I. Lieferung, V. Echinodermata. Leipzig.

(29) I882. Th. Lyman, Report on the Ophiuroidea dredged by H. M. S. Challenger. London.

(30) I882. A. E. Verrill, Restoration of the disk in Ophiurans; Ann. Mag. N. H. (5), vol. IX. London.

(3I) 1883. A. Stuxberg, Die Evertebraten-Fauna des sibirischen Eismeeres in: Die wissenschaftlichen Ergebnisse der Vegaexpedition von A. E. Freiherrn v. Nordenskiöld, Band I.

(32) I886. F. F ischer, Echinodermen von Jan Mayen in: Die internationale Polarforschung I882-1883; Die österreichische Polarstation Jan Mayen, III. Band. Wien I 886.

\section{Ophiura teres Lym.}

I860. (14) pag. 198, 257. - 1882. (29) pag. 11.

Die von Lyman für diese Species angegebene Variabilität der Radialschilder zeigt sich bei den vorliegenden Exemplaren aufs Deutlichste, indem von den sechs Exemplaren aus Californien nur eines, ebenso wie das Exemplar von den Galapagos-Inseln, von Granulationen nicht bedeckte Radialschilder besitzt.

Eigenthümlich ist eine bei allen Exemplaren aus Californien auftretende Zeichnung, es sind nämlich gegen das Armende zu immer zwei bis drei aneinanderstossende Armrückenplatten an den seitlichen Kanten gelb gerändert; diese so gezeichneten Platten sind aber stets durch mehrere einförmig graubraune Platten getrennt.

Galapagos-Inseln; Golf von Californien (F isher).

\section{Ophiura appressa Say.}

1825. (4) pag. I5I. - I882. (29) pag. 9.

Von den vorliegenden drei Exemplaren von Westindien zeichnet sich eines durch den Besitz von zwei Paaren kleiner unbedeckter Radialschilder aus, während die anderen drei Paare wie gewöhnlich von Granulationen bedeckt sind. An diesem Exemplare sind auch die sehr kleinen Seitenmundschilder nicht von Granula bedeckt und somit deutlich erkennbar. Auch die Form der Mundschilder selbst ist von der der beiden anderen Exemplare etwas verschieden; sie sind hier nämlich an ihrem aboralen Theile schmaler, am oralen aber stumpfer. Zwei Mundschilder dieses Thieres besitzen an ihrer peripheren Seite je eine kleine accessorische Platte.

St. Martha; Florida (Cambridger Museum); St. Thomas (Riise).

\section{Pectinura spinosa Ljn.}

1866. Ophiarachna spinosa (18), pag. 305. - I882. (29), pag. 17.

Das eine vorliegende Exemplar stimmt mit Ljungman's Beschreibung (i 8, pag. 305) vollständig überein, nur die Anzahl der Armstacheln ist etwas geringer, nämlich blos I I-I 2 statt I 3-I 5. Die Granula auf der Bauchseite der Scheibe sind an einigen Stellen ziemlich lang, fast stachelartig.

Die Farbe des getrockneten Thieres ist weisslichgrau; die Arme haben dunklere, bräunliche Querbinden.

Dschidda, Dr. Billitzer.

\section{Pectimura stellata Ljn.}

1866. Ophiarachna stellata Ljn. (18), pag. 305. - I882. (29) pag. 15.

Scheibe i 7 Mm. Durchmesser, Armlänge 6o Mm. Radialschilder fast ein Viertel so lang als der Durchmesser der Scheibe. Färbung des Thieres braun, die Radialschilder 
lichter und dunkler braun marmorirt; die Rückenplatten der Arme tragen an ihrem aboralen Rande mehrere lichtere Flecken.

Singapore (Salmin).

\section{Ophiolepis cincta M.-Tr.}

I842. (6) pag. 90. - I882. (29) pag. I9.

Einzelne Exemplare aus dem Rothen Meere zeichnen sich durch bedeutende Grösse aus, sie haben einen Scheibendurchmesser von $17 \mathrm{Mm}$. und eine Armlänge von $65 \mathrm{Mm}$. Die Färbung ist gelblich bei den Alkoholexemplaren, graulichweiss bei den trockenen. Die Arme zeigen auf der Rückenseite meist eine dunklere Bänderung, die von je vier bis sechs aneinanderstossenden, dunkler gefärbten Gliedern herrührt; die einzelnen Bänder sind meist durch drei bis fünf heller gefärbte Glieder getrennt.

Die Färbung des trockenen Exemplares von Mauritius ist oben röthlichbraun, unten gelblich; die Arme zeigen oben lichtere Querbinden. Bei den vorliegenden Thieren befindet sich am aboralen Rande der Arm-Rückenschilder ein Saum von kleinen Schüppchen, bei den Bauchschildern fehlt hingegen ein solcher. Vergl. (6) pag. go.

Tor, von Frauenfeld; Dschidda, Dr. Billitzer; Mauritius, Robillard; Mossambique, Peters; Cebu, Dr. Körbl.

\section{Ophioplocus imbricatus M.-Tr.}

I842. Ophiolepis (6), pag. 93. - I882. (29) pag. 20.

Die Exemplare von Réunion und Timor zeichnen sich durch sehr bedeutende Grösse aus, der Scheibendurchmesser beträgt bei dem grössten Thiere $23 \mathrm{Mm}$., die Armlänge circa ı $\mathrm{Cm}$. Die Grösse der Radialschilder variirt bei den vorliegenden Exemplaren ziemlich bedeutend. Sie sind bei der Form von Réunion, so wie sie Müller und Troschel beschreiben, "schwarze, glänzende, fein granulirte Stellen, nicht grösser als eine Schuppe«.

Insel Réunion, Dr. Körbl; Mossambique, Peters; Nicobaren, Novara-Expedition; Timor; Enosima, Dr. Körbl; Japan, Dr. von Roretz.

Ophioglypha albida Forbes. Taf. XII, Fig. 5 und 6.

I839. Ophiura albida (5), pag. I25. - I882. (29) pag. 76.

Wenngleich die Unterschiede dieser Species von den mit ihr in Gesellschaft lebenden Ophioglypha-Arten bereits von anderen Autoren eingehend dargestellt wurden (vergl. І2, pag. 39; г6, pag. 429 uind 24, pag. 369), erlaubte ich mir dennoch, diese Form, des besseren Vergleiches halber, neben den diesbezüglichen mit ihr verwandten abzubilden. Ich möchte hier nur noch speciell auf die entschieden andere Form der Radialschilder, der Papillen am Armursprunge, sowie auch auf die verschiedene Form der Mundpapillen gegenüber Ophioglypha Grubii hinweisen. Auch der mit keinen Papillen versehene Rand der Genitalspalten dürfte als ein nicht unwichtiges, unterscheidendes Merkmal gegenüber von Ophioglypha Grubii zu betrachten sein. Die Unterschiede in Hinsicht des Baues der Arme und seiner Beschilderung wurden schon von v. Marenzeller eingehend besprochen und bedürfen hier keiner weiteren Auseinandersetzung. Bemerkenswerth wäre höchstens noch, dass bei fast allen Exemplaren von Ophioglypha albida in der Mitte des interbrachialen Scheibenrandes eine grössere Platte liegt, welche bei Ophioglypha Grubii fehlt.

Die Exemplare von Christiania unterscheiden sich von den übrigen durch etwas längere Armrückenschilder. 
Bai von Muggia, Rovigno, Pola, Lussin, von Marenzeller; Lesina, Heller; St. Malo, von Marenzeller; Bohus (Stockholmer Museum); Christiania, von Frauenfeld; Norwegen.

\section{Ophioglypha affinis Lütk. Taf. XII, Fig. I und 2. \\ I 858. Ophiura affinis (12), pag. 45, pl. II, Fig. Ioa, b. - 1882. (29) pag. 77.}

Die vorliegenden Exemplare dieser Species (vier kleine jugendliche von Professor Loven und sechs grössere von Norman eingesandt) lassen einige Merkmale erkennen, welche in Lütken's Beschreibung ( 12 , pag. 45) nur kurz berührt werden. Vor Ailem fällt die Bekleidung der Scheibenoberseite sehr ins Auge, indem, wie auch schon Lütken angibt, um die grossen Schilder ein Kranz von sehr kleinen liegt, ein Verhältniss, das ungemein an manche Formen von Ophiocten, speciell Ophiocten amitinum Lym. (r 7 , pag. ı6, Taf. II, Fig. 8) erinnert. Die sehr stark gekielten Rückenschilder der Arme nehmen am Ursprung des Armes die ganze Oberseite desselben ein und sind dort dreimal so breit als lang; weiter nach aussen zu werden sie schmäler und länger, und die Arm-Seitenplatten bilden einen Theil der Bedeckung der Armoberseite. Gegen das Ende des Armes zu ist der von oben sichtbare Theil jeder Arm-Seitenplatte circa ebenso breit wie die Arm-Rückenplatte, diese ist hier circa $2^{1} / 2$ mal so lang als breit. An der innersten Arm-Füsschenöffnung, die zwischen dem Seitenmundschild und der benachbarten innersten Arm-Bauchplatte liegt, ist ebenfalls nur eine Tentakelschuppe zu sehen. Die innerste unpaare Mundpapille ist viel grösser als die übrigen und ragt ziemlich weit nach innen vor, auf sie folgen jederseits zwei kurze konische und zu äusserst endlich eine sehr schmale bandförmige Mundpapille.

Nordsee (Stockholmer Museum); Shetlands-Inseln (Norman).

Ophioglypha Grubii Heller. Taf. XII, Fig. 3 und 4.

1862. Ophiura Grubii (16), pag. 43I, pl. II, Fig. I3-16. - I882. (29) pag. 77.

Die Vergleichung, die von Marenzeller (7, pag. 368) zwischen vier ganz jungen, von Loven eingesandten Exemplaren von Ophioglypha affinis aus der Nordsee einerseits und zwei Originalexemplaren der Ophioglypha Grubii Heller, sowie mehreren von ihm bei Triest gefundenen Ophiuriden andererseits anstellte, hatte keine wesentlichen Unterschiede zwischen den Thieren aus der Nordsee und aus der Adria ergeben, weshalb er die Vereinigung der Ophioglypha Grubii Heller mit Ophioglypha affinis vorschlug. Seit vorigem Jahre ist die hiesige Sammlung in den weiteren Besitz von sechs ausgewachsenen Exemplaren der Ophioglypha affinis von den Shetlands-Inseln gelangt, und an diesen zeigen sich nun neben den schon von v. Marenzeller namhaft gemachten Unterschieden noch andere, welche eine Trennung der Nordseeform von der adriatischen ausreichend begründen. In der von Heller gegebenen Beschreibung sind folgende, hauptsächlich mit Hinblick auf Ophioglypha affinis wichtige, Merkmale hinzuzufügen. Die Beschilderung der Scheiben-Rückenseite ist, wie dies schon von v. Marenzeller betont wurde, von ziemlich gleichgrossen Schildern gebildet, unter denen sich durch etwas bedeutendere Grösse eine centrale Platte und eine Rosette von fünf primären Schildern auszeichnen. Der Papillenkamm am Scheibenrande ober dem Ursprung der Arme ist aus längeren, zarteren und spitzer zulaufenden Papillen gebildet als bei Ophioglypha affinis. Die nur wenig gekielten Rückenschilder der Arme bedecken auch am Armursprung nicht die ganze Rückenseite des Armes, sondern lassen rechts und links einen Streifen für die Seitenarmplatten frei. Die Mundschilder sind etwas weniger lang als bei Ophioglypha affinis und haben neben dem innersten Theil des Genital- 
schlitzes eine kleine Einbuchtung. Die Mundpapillen sind sämmtlich konisch und von nicht sehr verschiedener Länge. Die Bekleidung der Arm-Bauchseite stimmt mit der von Ophioglypha affinis vollkommen überein. An den innersten Armfüsschenporen, welche zwischen Seitenmundschild und innerster Arm-Bauchplatte liegen, befinden sich 8- 10 in zwei Reihen gestellte Tentakelschuppen, an den nächsten 2-3 Paaren von Oeffnungen je $4-2$, an den weiter nach aussen liegenden aber nur je eine solche.

Ich kann nicht umhin, an dieser Stelle der Ophiura abyssicola Forbes zu gedenken, welche seit ${ }_{1} 84^{3}$ nicht mehr im Mittelmeere aufgefunden worden zu sein scheint. Lütken will in ihr ein Ophiocten erkennen, weil der am Armursprung liegende Papillenkamm über der Mitte der Arme nicht unterbrochen ist. Mir scheint diese Auffassung nicht genügend sicher zu sein, da die Forbes'sche Beschreibung äusserst kurz und die beigegebene Abbildung ziemlich mangelhaft ist, und es wäre immerhin möglich, dass wir es nur mit einer Ophioglypha zu thun haben, welche vielleicht keine andere Art ist als obige von Heller aufgestellte.

Bai von Muggia, von Marenzeller; Lesina, Heller.

\section{Ophioglypha robusta Ayr.}

I851. Ophiolepis robusta (8), pag. 134. - 1882. (29) pag. 77.

Die drei in der hiesigen Sammlung vorhandenen Originalexemplare von Ophiolepis Tenorii, Müller und Troschel gehören sicher dieser Species an, dagegen sind dieselben, wie dies auch schon Ludwig (27, pag. 553) angibt, nicht identisch mit Delle Chiaje's Ophiura Tenorii, welche Form vermuthlich mit Ophiactis virens zusammenfällt. Da Ophioglypha robusta seither nie im Mittelmeer beobachtet wurde, ist wohl anzunehmen, dass dieser von Müller und Troschel (6, pag. 93) bezeichnete Fundort unrichtig angegeben wurde.

Bohus (Stockholmer Museum); Jan Mayen, F. Fischer; Grönland (Stockholmer Museum); Spitzbergen (Stockholmer Museum); erste österreichisch-ungarische Polarexpedition ( $75^{\circ} \mathrm{n}$. Br., $57^{\circ}$ ö. L. und $76^{\circ} \mathrm{n}$. B., 6 I $^{\circ}$ ö. L.), Dr. Kepes.

\section{Ophioglypha nodosa Lütk.}

1854. Ophiura nodosa (10), pag. 6. - 1882. (29) pag. 78.

Diese Form war bis vor Kurzem nur aus dem nördlichen Theile des atlantischen Oceans bekannt; sie wurde erst von der Vega-Expedition aus dem sibirischen Eismeere, etwas westlich von der Lenamündung und etwas westlich von der Koljutschin-Bai (vergl. 3i, pag. 55 I und 552), mitgebracht. Die mir von der Beringstrasse vorliegenden Exemplare stammen somit von einem noch etwas weiter östlich gelegenen Fundorte. I 2 Meilen östlich von den King-Islands, Beringstrasse (F is her); Spitzbergen (Stockholmer Museum).

\section{Ophiactis Savignyi M.-Tr.}

1842. Ophiolepis Savignyi (6), pag. 95. - I882. (29) pag. 115.

Während die übrigen Exemplare typische sind, unterscheidet sich das Exemplar aus dem Golf von Siam durch einige Merkmale; es sind die Radialschilder kürzer, ihre Länge ist nur ein Viertel des Scheibendurchmessers, während sie bei den übrigen Exemplaren circa ein Drittel desselben beträgt. Ferner ist die mittlere der drei die benachbarten Radialschilderpaare trennenden Schilderreihen (bei den übrigen Exemplaren sind meist fünf vorhanden) aus auffallend grossen Schildern gebildet; auch die Form der Rückenschilder der Arme ist hier fächerförmig, während sie sonst quer elliptisch 
ist. Schliesslich ist hier stets nur eine Mundpapille vorhanden, während bei den übrigen Exemplaren meist deren zwei auftreten und sehr selten blos eine einzige vorkommt. Golf von Siam (Salmin); Arru-Inseln, Dr. Wolf; Sandwich-Inseln (Cambridger Museum); Honolulu (Stockholmer Museum); Sidney, Dr. Wolf; Golf von Californien (Fisher); Westindien, Riise.

Ophiactis resiliens Lym. Taf. XIII, Fig. I9 und 20.

1879. (26) pag. 36, pl. XIII, Fig. 362-364. - I882. (29) pag. I15, pl. XX, Fig. 7-9.

Wenngleich die vorliegenden Exemplare nicht vollständig Lyman's Beschreibung entsprechen, dürften sie doch wahrscheinlich dieser Species angehören. Scheibendurchmesser des ausgewachsenen Thieres 7 Mm., Armlänge 45 Mm., Scheibe und Arme ziemlich flach. Schildchen auf der Scheibenoberseite ziemlich klein, eine kreisrunde centrale Platte vorhanden. Gegen den Scheibenrand zu stehen kleine, konische Stacheln. Radialschilder klein und schmal, circa ein Fünftel des Scheibendurchmessers lang, je zwei eines Paares durch 4-6 Schilder getrennt. Die ersten drei Rückenschilder der Arme klein, die nächsten gross und queroval, Länge zur Breite $1: 2$ bis $2 \cdot 5$. Nicht selten sind einzelne Rückenschilder oder eine Reihe aufeinander folgender in der Mittellinie des Armrückens getheilt. Am Ursprung des Armes fünf Stacheln, wovon der oberste am längsten und so wie der benachbarte ziemlich flach ist, die unteren sind mehr konisch. Interbrachialräume der Scheibenunterseite ohne deutliche Schilder, wohl aber bestachelt. Mundschilder fast kreisrund. Seitenmundschilder der benachbarten Paare sich fast berührend. Die zwei sehr grossen Mundpapillen nehmen fast die ganze Länge der Seiten des Mundwinkels ein. Bauchschilder der Arme ebenso breit als lang, fast kreisförmig. Eine sehr grosse Tentakelschuppe. Farbe des Thieres bräunlich, einzelne Rückenschilder der Arme mit etwas dunkleren, unregelmässigen Zeichnungen.

Ein jüngeres Exemplar hat einen Scheibendurchmesser von 3.5 Mm., bei einer Armlänge von $18 \mathrm{Mm}$. Auch dieses Thier hat mehrere Armrückenschilder in der oben geschilderten Weise getheilt.

Sidney, Dr. Wolf.

\section{Ophiactis nama Lym.}

1879. (26) pag. 38, pl. XIII, Fig. 350-352. - I882. (29) pag. II7, pl. XX, Fig. I6-18.

Mehrere vorliegende in einem Hyalonema Sieboldii aufgefundene Exemplare von Ophiactis unterscheiden sich hauptsächlich durch ihre geringere Grösse von obiger Species; sie haben nämlich einen Scheibendurchmesser von nur $2 \mathrm{Mm}$. gegenüber dem von Lyman mit $6 \mathrm{Mm}$. angegebenen. Die Armrücken und Arm-Bauchplatten sind bei den vorliegenden Thieren etwas länger, als sie Lyman zeichnet; in allen anderen Beziehungen stimmen diese Thiere aber so sehr mit Ophiactis nama überein, dass ich glaube, sie als dieser Species angehörig betrachten zu sollen.

Japan, Dr. von Roretz.

\section{Ophiactis Ljungmani n. sp. Taf. XII, Fig. 9- $\mathrm{I}$.}

Scheibendurchmesser 3.5-5 Mm., Armlänge 35-45 Mm., fünf, selten vier Arme. Scheibenoberseite mit mehr weniger dachziegelartig sich deckenden Schildern bekleidet, die zum Theil kurze, kräftige, konische Stacheln tragen. Letztere sind bei der Form von Porto Prince zahlreicher vorhanden als bei der westafrikanischen Form (s. Fig. I I), Radialschilder sehr gross, so lang wie ein Drittel des Scheibendurchmessers. Zwischen den Radialschilderpaaren meist fünf Reihen von Schildern. Rückenschilder der Arme 
sehr breit, oval; Länge zur Breite ı :3; die orale und aborale Begrenzungslinie, besonders gegen die Mitte des Armes zu, ziemlich gerade. An der Armbasis meist sechs Armstacheln, wovon der zweite, von oben gezählt, am längsten ist; Stachelquerschnitt ziemlich kreisrund. Interbrachialräume auf der Scheibenunterseite ebenfalls mit Stacheln versehen. Mundschilder rund, circa ebenso breit als lang. Seitenmundschilder der benachbarten Paare berühren sich fast. 2-3 Mundpapillen; die Form von Porto Prince besitzt deren fast stets nur zwei, während die westafrikanische Form häufiger die Zahl drei aufweist. Bauchschilder der Arme fast gleich lang wie breit, quadratisch bis achteckig, ihre seitlichen Ränder, sowie der aborale Rand sind etwas wulstig. Ein e sehr grosse Tentakelschuppe. Farbe oben graulichweiss, unten weiss. Arme mit etwas dunkleren Binden an der Oberseite.

Diese Form ist am nächsten verwandt mit der von Ljungman (Vestend. och atlant. Oph.; Öfvers. af k. Vet. Ak. Förh. I871) beschriebenen Ophiactis Mülleri Lütk. var. quinqueradia, doch unterscheidet sie sich wenigstens von den mir vorliegenden Exemplaren von Ophiactis Mülleri Lütk. so sehr, dass ich glaube, sie als eigene Species betrachten zu sollen.

$0 \cdot 7^{\circ}$ n. B., $23-25^{\circ}$ w. L. (Schilling); Porto Prince (Haïti), Bobrik.

\section{Ophiactis macrolepidota n. sp. Taf. XII, Fig. I 2 und I 3.}

Scheibendurchmesser 3 Mm., Armlänge I 2 Mm., sechs Arme. Scheibe oben mit auffallend grossen Schildern bedeckt, welche aber nur an der Scheibenperipherie und auch dort nur sehr wenige Stacheln tragen. Radialschilder schmal, kaum ein Viertel so lang als der Scheibendurchmesser. Rückenschilder der Arme fächerförmig, nicht ganz doppelt so breit als lang. An der Armbasis vier Armstacheln von fast kreisrundem Querschnitt. Interbrachialräume der Scheibenunterseite ohne deutliche Schilder, aber mit einigen kleinen Stacheln versehen. Mundschilder beinahe ebenso breit als lang und, ebenso wie die deltoidischen Seitenmundschilder, ziemlich undeutlich begrenzt. Eine Mundpapille. Bauchschilder der Arme fünfeckig. Die Seitenschilder der Arme berühren sich, mit Ausnahme der ersten Armglieder, ein kurzes Stück in der Medianlinie der Armunterseite an der approximalen Seite der einzelnen Glieder. Ein e sehr grosse Tentakelschuppe. Färbung des Thieres bräunlichgrau.

Sidney, Dr. Wolf.

\section{Ophiactis Lïtkeni n. sp. Taf. XII, Fig. 7 und 8.}

Scheibendurchmesser 2.5 Mm., Armlänge $12 \mathrm{Mm}$., fünf Arme. Scheibe oben mit sich etwas dachziegelartig deckenden, fein granulirten Schildern versehen; ein etwas grösseres, centrales Schild vorhanden. Radialschilder klein, meist nach innen zu durch ein schmales Schild getrennt. Zwischen den benachbarten Radialschildpaaren meist sechs Reihen von Schildern. Rückenplatten der Arme von der Armbasis bis gegen die Mitte des Armes an Grösse zunehmend, beinahe doppelt so breit als lang, querelliptisch. 4-5 Armstacheln, der zweite von oben am längsten, und zwar circa so lang als das Armglied, dem er angehört. Unterseite der Scheibe sehr zart beschildert; auch hier wie auf der Scheibenoberseite keine Stacheln vorhanden. Mundschilder etwas breiter als lang, rhombisch mit abgerundeten Ecken. Die Seitenmundschilder der benachbarten Paare berühren sich. Eine Mundpapille. Die Mundfüsschen scheinen Kalkeinschlüsse zu enthalten, da sie beim Trocknen des Thieres nicht collabiren, sondern steif aufgerichtet hervorragen. Die Bauchschilder der Arme sind anfangs etwas dreieckig, dann fast 
kreisförmig. Eine ziemlich grosse Tentakelschuppe. Farbe des Thieres oben grünlich, unten weisslich, mit Ausnahme der grünlich gefärbten Interbrachialräume der Scheibe. Fernando Po, Dr. Lip pe.

\section{Amphiura crassipes Ljn.}

I866. (I8) pag. 319. - I882. (29) pag. 142.

Die beiden vorliegenden, leider nicht sehr gut erhaltenen Exemplare gehören sicher dieser Species an, da sie in allen Merkmalen mit Ljungman's Beschreibung übereinstimmen. Speciell charakteristisch für diese Form sind der tiefe Einschnitt der Scheibe ober dem Armursprung, die eigenthümlich aufgerichteten Schildchen der Scheibenbedeckung, sowie die zwei ziemlich kleinen Tentakelschuppen. Nur die Anzahl der Armstacheln ist hier nicht acht, wie sie Ljungman angibt, sondern nur sieben. Die Armlänge ist jedenfalls sehr bedeutend; obgleich keiner der Arme vollständig erhalten ist, kann doch gesagt werden, dass bei einem Scheibendurchmesser von $8.5 \mathrm{Mm}$. die Arme mindestens $9 \mathrm{Cm}$. lang sind.

$3 \mathrm{I}^{\circ}$ I $3 \cdot 5^{\prime}$ s. Br., $50^{\circ}$ I I $66^{\prime}$ w. L. Bobrik.

\section{Amphiura candida Ljn.}

1866. (I8) pag. 318. - I882. (29) pag. 142.

Die vorliegenden vier Exemplare stimmen vollkommen mit Ljungman's Beschreibung überein, nur unterscheiden sich einzelne durch bedeutendere Grösse. Das grösste Exemplar hat einen Scheibendurchmesser von $8 \mathrm{Mm}$; die Arme übertreffen denselben circa um das Siebenfache. Die Färbung der Thiere ist gelblichweiss. Der zweite und dritte, zuweilen auch der vierte Armstachel, von unten an gerechnet, trägt an seinem Ende feine Dörnchen.

Japan, Dr. Körbl.

Amphiura Chiajei Forbes.

1843. (7) pag. I5 I. - I882. (29) pag. 142.

Die nordischen Exemplare stimmen mit den adriatischen vollkommen überein.

Grado; Lussin, von Marenzeller; Christiania, von Frauenfeld; Bohus (Stockholmer Museum).

\section{Amphiura Stimpsoni Lütk.}

I859. (13) pag. I16. - 1882. (29) pag. 143.

Das eine vorhandene Exemplar stimmt im Wesentlichen gut mit Lütken's Beschreibung überein, nur ist die Länge der Arme eine grössere.

Scheibendurchmesser $4 \mathrm{Mm}$., Armlänge circa $25 \mathrm{Mm}$. (alle Arme unvollständig). Scheibe oben mit mittelgrossen, sich dachziegelartig deckenden Schildern bedeckt. Länge der Radialschilder gleich einem Viertel des Scheibendurchmessers; Verhältniss ihrer Länge zur Breite circa 3:ı. Rückenschilder der Arme oval, Länge zur Breite I: 1 3. An der Armbasis fünf Stacheln, von denen die beiden obersten meist an ihrem Ende ein kleines aboral gestelltes Dörnchen tragen. Die einzelnen Stacheln von nahezu gleicher Länge, beiläufig von der eines Armgliedes. Bauchseite der Scheibe mit feineren Schildchen bedeckt. Mundschilder herzförmig, etwas länger als breit. Seitenmundschilder sich fast berührend. Aussen zwei Mundpapillen und weiter innen stehend eine schmale, dreieckige. Bauchschilder der Arme anfangs rechteckig, dann mehr sechseckig. Länge zur Breite 1 : $1 \cdot 3$. Eine Tentakelschuppe, nur an den ersten Gliedern am Armursprung zuweilen eine kleine Andeutung einer zweiten vorhanden. Färbung weisslich.

Porto Prince, Bobrik. 


\section{Amphiura constricta Lym.}

1879. (26) pag. 22, pl. XI, Fig. 295-298. - i882. (29) pag. I31.

Vollständig mit Lyman's Beschreibung übereinstimmend, nur sind bei dem vorliegenden Thiere nur fünf Armstacheln vorhanden, während Lyman sechs angibt. Das Exemplar hat einen Scheibendurchmesser von $3 \mathrm{Mm}$. und eine Armlänge von circa $18 \mathrm{Mm}$.

Sidney, Dr. A. Wolf.

\section{Amphiura glabra Lym.}

1879. (26) pag. 25, pl. XI, Fig. 308-310. - I882. (29) pag. 134.

Das eine vorhandene Exemplar stimmt mit Lyman's Beschreibung und Abbildung im Wesentlichen überein. - Als bemerkenswerthe Unterschiede wären nur die flache, äussere Mundpapille und die kurzen, kräftigeren Stacheln zu erwähnen; ich lasse übrigens hier eine kurze Beschreibung des vorliegenden Thieres folgen: Scheibendurchmesser $4 \mathrm{Mm}$. (alle fünf Arme unvollständig). Scheibenoberseite mit sich dachziegelartig deckenden, sehr fein granulirten Schildern bedeckt. Radialschilder ziemlich schmal, circa ein Fünftel so lang als der Scheibendurchmesser. Rückenschilder der Arme queroval, Länge zur Breite ı : г8. Fünf kurze kräftige Armstacheln, von denen der zweitoberste ziemlich flach ist. Scheibenunterseite ohne deutliche Schilder. Mundschilder klein, rhombisch, gleich breit als lang. Aeussere Mundpapille lang und flach; das an der Spitze des Mundwinkels liegende Paar derselben dick und rund. Bauchschilder der Arme quadratisch, oder etwas länger als breit. Eine Tentakelschuppe. Färbung gelblichweiss.

Japan; Dr. Körbl.

\section{Amphiura filiformis O. F. Müller.}

1776. Asterias filiformis (1) pag. 235. - 1882. (29) pag. I44.

Das einzige vorliegende, adriatische Exemplar unterscheidet sich von den nordischen durch stärkere Einbuchtung der Scheibe in den Interbrachialräumen und durch etwas grössere Schilder auf der Scheibenoberseite. Der zweite Armstachel, von unten an gezählt, hat bei allen Exemplaren an seinem Ende ein kleines, aboral gestelltes und meistens auch noch ein oralwärts gerichtetes Dörnchen.

Christiania, von Frauenfeld; Bohus (Stockholmer Museum); Pirano, Heller.

\section{Amphiura occidentalis Lym.}

I860. (14) pag. 194. - I882. (29) pag. I47.

Scheibendurchmesser I6 Mm., Armlänge $27 \mathrm{Cm}$., fünf Arme. Scheibenoberseite mit sehr zarten Schildern bedeckt. Radialschilder sehr klein, $2 \mathrm{Mm}$. lang, sich aussen berührend, innen getrennt. Rückenschilder der Arme fast sechseckig, $2^{1 / 2}$ mal so breit als lang. Drei kurze, konische Armstacheln. Scheibenunterseite mit äusserst zarten Schildern bedeckt. Mundschilder sehr klein, rhombisch, fast gleich breit als lang. Länge circa I Mm. Seitenmundschilder undeutlich begrenzt. Drei ziemlich gleich grosse Mundpapillen. Bauchplatten der Arme rechteckig, wenig breiter als lang, der distale Rand etwas concav. Zwei Tentakelschuppen. Färbung gelblichweiss.

Pugetsund, Dr. Steindachner.

Amphiura Mülleri n. sp. Taf. XIII, Fig. 25 und 26.

Das einzige vorliegende Exemplar steht der Amphiura Josephinae Ljn. nahe, da es der Hauptsache nach mit Ljungman's Beschreibung dieser Species übereinstimmt; 
aber die Form der äusseren Mundpapille ist hier eine mehr flache, die der Bauchschilder der Arme eine rechteckige, nicht fünfeckige, und schliesslich ist die Armlänge eine bedeutendere. Scheibendurchmesser $2.7 \mathrm{Mm}$., Armlänge $20 \mathrm{Mm}$. Scheibenoberseite mit sich dachziegelartig deckenden Schuppen bedeckt, von denen fünf grössere um ein ebenfalls etwas grösseres, centrales Schild eine Rosette bilden. Radialschilder ein Viertel so lang als der Scheibendurchmesser, ziemlich schmal und durch eine Schildchenreihe getrennt. Rückenschilder der Arme circa ebenso breit als lang, ihre aborale Seite länger als die orale, die Seitenkanten convex. Vier bis fünf ziemlich spitz zulaufende Armstacheln, von denen die längeren beiläufig so lang sind als ein Armglied. Bauchschilder der Arme rechteckig, etwas länger als breit ( $\left.{ }^{\circ} 4: \mathrm{I}\right)$. Mundschilder fast kreisrund, Seitenmundschilder dreieckig. Zwei Mundpapillen, von denen die nach innen zu liegende, wie dies bei diesem Genus meist der Fall ist, sich durch ihre bedeutende Grösse auszeichnet; weiter im Innern des Mundes sieht man an jeder Mundwinkelseite noch eine dritte, dreieckige Mundpapille. Bauchseite der Scheibe in den Interbrachialräumen mit sehr zarten Schildern bedeckt. Eine sehr kleine Tentakelschuppe. Farbe des Thieres weiss.

$0.7^{\circ}$ n. Br., $23-25^{\circ}$ w. L. (Schilling).

\section{Amphiura brevispina n. sp. Taf. XII, Fig. 14 und 15.}

Scheibendurchmesser $5 \mathrm{Mm}$., Armlänge $28 \mathrm{Mm}$., fünf Arme. Scheibenoberseite mit mässig grossen, etwas convexen Schildern bedeckt. Radialschilder lang, etwa ein Viertel des Scheibendurchmessers, dreimal länger als breit, sich aussen berührend, innen getrennt. Rückenschilder der Arme elliptisch, Länge zur Breite I : ${ }^{\cdot} 2$. Fünf sehr kurze, dicke, meist hohle Armstacheln, von denen die beiden untersten ganz besonders bauchig sind. Scheibenunterseite mit ganz undeutlichen Schildern versehen. Mundschilder fast gleich breit als lang. Seitenmundschilder der benachbarten Paare sich fast berührend. Aussen zwei Mundpapillen und eine stachelförmige, tiefer liegende. Bauchschilder der Arme quadratisch, mit etwas abgestumpften Ecken. Eine ziemlich kleine Tentakelschuppe. Färbung in Alkohol gelblichweiss.

St. Paul, Novara-Expedition.

\section{Ophionephthys phalerata Lym.}

I874. (23) pag. 229, pl. VI, Fig. 7-9. - I882. (29) pag. I52.

Die Radialschilder sind auf ihrer freien Seite gegen das Centrum zu von fünf Reihen von Schildchen umsäumt, nach aussen zu verringert sich die Anzahl der Reihen nach und nach bis auf eine einzige. Die Mundwinkel springen an dem vorliegenden Exemplar weiter nach innen vor, als dies Lyman abbildet. Die Stellung der Mundpapillen erinnert ungemein an Amphiura, die innere, infradentale ist sehr gross und aufgetrieben, die äussere, weit davon entfernte stachelförmig. In jenem Interradius, welchem das eine weit grössere Mundschild angehört, stehen dicht nebeneinander je zwei derartige, stachelförmige Papillen.

$$
\text { Japan, Dr. von Roretz. }
$$

\section{Ophionereis reticulata Say.}

I825. Ophiura reticulata Say. (4), pag. 148. - 1882. (29) pag. I62.

Das ziemlich kleine Exemplar von Westafrika unterscheidet sich von den übrigen durch tiefere Einschnitte der Scheibe in den Interbrachialräumen, durch grösstentheils unter der Scheibenhaut versteckte Beschuppung, welche nur an einigen Stellen am Scheibenrande deutlich sichtbar ist. Weiters ist die Form der Armrückenplatten eine 
mehr ovale und die Berührungslinie der benachbarten Platten kürzer als bei den übrigen Exemplaren. Die Radialschilder und accessorischen Arm-Rückenplatten sind denen der westindischen Exemplare sehr ähnlich. Auffallend sind noch zwei von den Radialschildern gegen das Scheibencentrum zu ziehende Furchen, zwischen welchen sich noch eine dritte Furche in der Verlängerungslinie der Medianlinie des Armes hinzieht. Die Mundwinkel springen hier etwas weiter gegen den Scheibenmittelpunkt vor. Die Mundschilder tragen an ihrem Aussenrande keine Genitalschuppen; letztere sind bei der westindischen Form an ihrem sichtbaren Rande, wie dies schon Lütken angibt, meist etwas gezähnt. Bauchschilder der Arme etwas länger als breit. Färbung des Thieres gelblichweiss mit dunklen Querbinden über dem Armrücken, bei jedem fünften bis sechsten Gliede. Ein grösseres Material wird erst darüber Aufschluss geben, ob die hinsichtlich ihrer Unterschiede von der typischen Ophionereis reticulata beschriebene Form, eine neue Species, oder nur eine locale Varietät vorstellt.

Cap Florida (Cambridger Museum); Westindien (Riise); $0.7^{\circ}$ n. Br., 23 bis $25^{\circ}$ w. L. (Schilling).

Ophionereis porrecta Lym. Taf. XII, Fig. I8.

I860. (14) pag. 260. - I882. (29) pag. 162.

Wenngleich das vorliegende Exemplar mit Lyman's Beschreibung obiger Art (vgl. 17, pag. 147) nicht vollkommen übereinstimmt, zweifle ich nicht, dass es doch dieser Species angehört, da in allen wichtigen Merkmalen (bedeutende Länge der Arme, drei kurze Armstacheln etc.) keine wesentlichen Verschiedenheiten zu finden sind. Ich lasse eine kurze Beschreibung des Thieres folgen:

Scheibendurchmesser $6 \mathrm{Mm}$., Armlänge circa 5o Mm. Die Armrückenschilder sind deltoidisch, breiter als lang, der breitere Theil liegt oralwärts. Ein Mundschild trägt an seinem äusseren Rande deutliche Oeffnungen. Seitenmundschilder dreieckig, ziemlich klein. Zehn Mundpapillen, die äusserste aber kleiner und spitzer. Keine deutlichen Papillen längs des Genitalschlitzes. Bauchplatten der Arme ebenso lang als breit, die orale und aborale Seite etwas convex, die laterale etwas concav. Färbung der Scheibe gelbbraun mit rostbraunen Zeichnungen. Arme von derselben Grundfarbe mit dunkelbraunen Binden über circa jedes dritte Glied. Alle übrigen nicht namhaft gemachten Punkte stimmen mit Lyman's Beschreibung vollkommen überein.

Japan, Dr. Körbl.

\section{Ophiocoma scolopendrina Lmk.}

I8I6. Ophiura scolopendrina Lmk. (3) pag. 544. - I882. (29) pag. I7o.

Die Vergleichung der zahlreich vorliegenden Exemplare von Ophiocoma scolopendrina mit den als Ophiocoma erinaceus M.-Tr. bestimmten, führte mich zu der Ansicht, welche schon H. Ludwig (28, pag. 4) ausgesprochen, dass es nicht möglich sein wird, diese beiden Formen von einander zu trennen. Färbungsvarietäten und kleine Verschiedenheit der Beschilderung, Unterschiede, auf welche Lyman hier besonders hinweist, kommen in dieser Thierclasse so häufig vor, dass darauf hin wohl kaum eine Species abgetrennt werden kann. Der Unterschied, welchen Lütken anführt, dass die Scheibenunterseite bei Ophiocoma erinaceus ganz nackt, dagegen bei Ophiocoma scolopendrina theilweise mit Granulationen bedeckt sei, dürfte auch nicht stichhältig sein, da es unter den vielen vorliegenden Formen in dieser Hinsicht die verschiedensten Uebergänge gibt. Die Anzahl der Tentakelschuppen, welche für beide Formen stets mit zwei angegeben wird, zeigt auch verschiedene Variationen. Während die Exemplare von 
Süd-Ostafrika und aus dem Rothen Meere thatsächlich meist zwei solche Schuppen besitzen, haben die Exemplare aus der Südsee grösstentheils nur eine. Ich vermuthe deshalb, dass auch die Müller und Troschel'sche Species Ophiocoma Schönleinii, deren sonstige Merkmale jenen von Ophiocoma scolopendrina sehr ähnlich sind, hieher zu ziehen sein dürfte. Weiters gibt es aber auch zahlreiche Exemplare, welche etwa bis zur Hälfte des Armes zwei, gegen das Ende zu aber nur eine Tentakelschuppe besitzen, ein Umstand, welcher zeigt, dass auch diesem Merkmale nur ein untergeordneter Werth beizumessen ist. Auf die sehr verschiedene Länge und Form der Armstacheln wurde auch schon von Anderen aufmerksam gemacht (vgl. Taf. XIII, Fig. 2 I - 24), und ich brauche hier nur zu wiederholen, dass bei manchen Exemplaren die Stachellänge der Breite der Armrückenplatte gleichkommt, bei anderen aber diese um das Dreifache übertrifft. Oft sind die unteren Armstacheln, besonders in der Nähe der Scheibe, sehr flach, zuweilen ist dies bei sämmtlichen Armstacheln der Fall, hingegen ist bei anderen Exemplaren der oberste Armstachel ungemein dick und angeschwollen.

Tor (Rothes Meer), von Frauenfeld; Dschidda, Dr. E. Billitzer; NikobarInseln, Novara-Expedition; Insel Réunion, Dr. Körbl; Mossambique, Peters; Amboina, Dr. Doleschal; Tahiti, Novara-Expedition; Australien; Philippinen; Cebu, Dr. Körbl; Torresstrasse, Banda-Inseln, Viti-Inseln, Dr. A. Wolf.

\section{Ophiocoma brevipes Pet.}

1852. (9) pag. $85 .-1882$. (29) pag. 172.

Die zwei Exemplare von Mauritius zeichnen sich durch ihre auffallende Grösse aus, sie haben einen Scheibendurchmesser von $25 \mathrm{Mm}$. und eine Armlänge von r $30 \mathrm{Mm}$.

Tor, von Frauenfeld; Nikobar-Inseln, Novara-Expedition; Mauritius (Robillard); Mossambique, Peters.

\section{Ophiocoma Valenciae M.-Tr.}

I842. (6) pag. I02. - I882. (29) pag. 172。

Diese Species ist durch Müller's und Troschel's, wenn auch kurze Beschreibung, so gut charakterisirt, dass es kaum nöthig ist, weitere Details hinzuzufügen. Bemerkenswerth wäre höchstens, dass die Bekleidung der Bauchseite der Scheibe mit Granulationen auch hier verschieden dicht ist. Sowohl das eine Originalexemplar, als auch andere vorliegende Exemplare haben fast die ganze Scheibenunterseite gleichmässig mit Granula bekleidet, wogegen das zweite Originalexemplar an den die Genitalspalten begrenzenden Partien, bei sonstiger vollkommener Uebereinstimmung, nackt ist. Ich erlaube mir auf dieses Verhältniss im Hinblick auf das über diesen Punkt bei Ophiocoma scolopendrina Gesagte aufmerksam zu machen. An jeder Mundwinkelseite stehen 3-4 Mundpapillen, von denen die äusserste meist etwas grösser ist. Die Seitenmundschilder sind dreieckig, mit concaven Rändern. Die Tentakelschuppe ist gross und oval. Färbung gelblichweiss bis bräunlich.

Rothes Meer. (Originalexemplare.)

Ophiocoma marmorata n. sp. Taf. XII, Fig. i6 und i 7 .

Scheibendurchmesser $9 \mathrm{Mm}$., Armlänge $5 \mathrm{Cm}$. Scheibe oben und unten, mit Ausnahme eines schmalen Streifens neben den Genitalspalten, mit Granula bedeckt. Rückenschilder der Arme oval bis fächerförmig, circa anderthalbmal so breit als lang. Mundschilder oval, länger als breit. Seitenmundschilder klein, dreieckig. Der die Genitalspalten begrenzende Scheibenrand ist gegen das Mundschild zu mit Granula besetzt. Unter den Zähnen steht meist eine Reihe mit drei und eine Reihe mit je zwei Papillen. 
I o- I I Mundpapillen. Vier Armstacheln, der oberste länger und stärker, die drei anderen fast gleich lang. Bauchschilder der Arme kaum länger als breit, viereckig, der aborale Rand convex, die Seitenränder etwas concav. Zwei ziemlich grosse Tentakelschuppen. Färbung des Thieres gelblichweiss, mit brauner Marmorirung auf der Scheibenoberseite und braunen Binden über den Armrücken.

$0.7^{\circ}$ n. Br., $23-25^{\circ}$ w. L. (Schilling).

\section{Ophiothrix fragilis Abild.}

1789. Asterias fragilis (2), pag. 28, pl. 98. - 1882. (29) pag. 224.

Diese Species unterscheidet sich, wie dies schon Lütken (20, pag. 53) angibt, von der jedenfalls adriatischen Ophiothrix fragilis M.-Tr. (vgl. 24, pag. 370-37I) durch dickere Arme, kräftigere, aber feiner gezähnte Armstacheln und einen Scheibenbesatz, welcher meist nur an der Peripherie aus mehrspitzig endenden Dörnchen besteht, während er gegen die Scheibenmitte zu auch bei erwachsenen Exemplaren nur aus mehr warzenförmigen Knötchen gebildet ist, zwischen denen keine oder nur sehr wenige, dicke, kurze und stumpfe Stacheln stehen. Die Radialschilder sind bei allen vorliegenden Exemplaren vollständig nackt.

Dänische Küste (Kopenhagener Museum); Nordsee, Bobrik; Great Cumbray, Christiania, von Frauenfeld; Cancale, von Drasche; Bohus (Stockholmer Museum); Norwegen.

\section{Ophiothrix alopecurus M.-Tr. Taf. XIII, Fig. 36-39.}

1842. (6) pag. III. - I882. (29) pag. 224.

Schon mehrere bedeutende Forscher haben sich eingehender mit den in der Adria und im Mittelmeer lebenden Repräsentanten der Gattung Ophiothrix beschäftigt (vgl. 23, pag. 224 ; 24, pag. 369; I , pag. 74), sind hiebei aber zu einigermassen verschiedenen Resultaten gelangt; Lyman führt schliesslich (29, pag. 224, 225) als im Mittelmeer vorkommend an: Ophiothrix echinata M.-Tr. (non Lütk. nec Ljn.), Ophiothrix lusitanica Ljn. und Ophiothrix quinquemaculata M.-Tr.; als in der Adria lebend: Ophiothrix echinata M.-Tr. und Ophiothrix alopecurus M.-Tr.

Die Ophiothrix fragilis Abild. wird nach Lyman und wohl mit vollem Rechte als Bewohnerin der nordeuropäischen Meere angeführt, da sie sich, wie dies schon Lütken (13, pag. 53) zeigte, in mehrfacher Weise von der adriatischen Form unterscheidet. Während das hier aus dem Mittelmeer vorliegende Material ein sehr bescheidenes ist, hat sich jenes aus der Adria seit dem Erscheinen der »Revision adriatischer Seesterne « (24, pag. 37r), insbesondere durch Herrn Dr. von Marenzeller's eigene Aufsammlungen, bedeutend vergrössert, und es liegen jetzt zahlreiche Exemplare von verschiedenen Punkten der dalmatinischen Küste und Inseln vor.

Ueberblickt man die adriatischen Exemplare, so findet man so bedeutende Unterschiede in Hinsicht auf Färbung und Stachelbekleidung, dass man darnach, wenn man einzelne marcante Formen herausgriffe, im Stande wäre, mindestens 5-6 wohlcharakterisirte Species zu beschreiben; bei genauerer Betrachtung zeigt sich jedoch, dass alle diese Formen durch so viele Uebergangsglieder, welche die verschiedensten Combinationen von Eigenschaften zeigen, verbunden sind, dass es mir aus diesem Grunde wenigstens bis heute am zweckmässigsten erscheint, für die Adria nur eine einzige, aber sehr variable Ophiothrix-Species unter dem Namen Ophiothrix alopecurus M.-Tr., anzunehmen. 
Wenngleich mit Recht gegen die von Lyman eingeführte Anwendung des Namens Ophiothrix alopecurus auf die grosse, langstachlige Ophiothrix-Form der Adria Einwürfe gemacht wurden (vgl. 24, pag. 370 ), dürfte es berechtigt erscheinen, den ganzen unten geschilderten Formenkreis unter dem obigen Namen zusammenzufassen, da derselbe von Müller und Troschel ebenfalls auf eine adriatische und wahrscheinlich zur Gruppe 4 (s. unten) gehörige Form basirt wurde, wobei nur zu bemerken ist, dass mit ihm Ophiothrix fragilis M.-Tr. und Ophiothrix fragilis var. tenuispina Sars zusammenfallen. Die zahlreichen Varietäten, welche, wie zum Theil schon angedeutet, auf Färbungs-Verschiedenheiten, verschiedenartige Bestachelung der Scheibe und der Arme, sowie auf dem Vorhandensein oder Fehlen des für viele Exemplare charakteristischen Knötchens auf den Armrückenschildern beruhen, sollen in Folgendem, nach diesen Merkmalen gruppirt, in Kürze besprochen werden. Von einer Benennung der einzelnen Gruppen als verschiedene Varietäten obiger Species muss Umgang genommen werden, da dieselben zu wenig scharf von einander abgegrenzt sind.

Gruppe I, Taf. XIII, Fig. 36 und 37. - Scheibendurchmesser r o Mm., Armlänge $80 \mathrm{Mm}$. Scheibe kreisrund. Scheibenrücken dicht, mit $\mathrm{I}^{\mathrm{1}} / 2-2 \mathrm{Mm}$. langen, wenig dornigen Stacheln besetzt, zwischen denen entweder gar keine oder wenige, $2-4$ spitzig endende Cylinderchen stehen. Radialschilder nackt, $3 \mathrm{Mm}$. lang. Rückenschilder der Arme am aboralen Rande etwas dreilappig, in ihrer Mitte mit einem Knötchen versehen; zuweilen steht sogar in der Mitte des adoralen Randes derselben ein Stachel. Armstacheln 6-7, der oberste kurz und zart, der zweite von oben am längsten, circa $3 \mathrm{Mm}$. lang und mit I 5- I 8 Dörnchen an jeder Seite versehen. Bauchseite der Scheibe auch mit zahlreichen Stacheln bekleidet. Mundschilder circa doppelt so breit als lang, nach aussen in Verbindung mit zwei Genitalschuppen. Seitenmundschilder nicht sehr deutlich contourirt. Mundpapillen meist 26-29, hievon an der Peripherie 19-20, innen 7-9. Genitalplatte deutlich sichtbar. Bauchschilder der Arme fast quadratisch. Eine kleine Tentakelschuppe. Färbung der Scheibe und Arme oben bläulichgrün, letztere zuweilen etwas dunkler. Scheibenunterseite grünlich. Armunterseite etwas röthlich. Stacheln weiss bis grünlich.

Diese Form ist in der Bai von Muggia die häufigste. Die Exemplare von Pirano haben sehr dunkel gefärbte Radialschilder.

Gruppe 2. - Scheibendurchmesser bis 17 Mm., Armlänge 70 Mm. Die Scheibe ist ausgesprochen fünfeckig, die Ecken des Pentagons liegen interbrachial, die Kanten sind nicht gerade, sondern bilden einen stumpfen, nach innen einspringenden Winkel, dessen Scheitel über der Armbasis liegt. Alle übrigen Merkmale stimmen mit den, bei der Besprechung der Gruppe I namhaft gemachten, vollkommen überein. Die Exemplare aus der Bai von Muggia besitzen auf der Scheibenoberseite ein grosses, hellgefärbtes Pentagon, dessen Kanten der äusseren Peripherie der Scheibe in einem Abstande von circa $\mathrm{I}^{1} / 2 \mathrm{Mm}$. parallel laufen. Der das Fünfeck umsäumende Streifen der Scheibenoberseite ist, ebenso wie die Bauchseite der Scheibe und die Rückenschilder der Arme, fast schwarz gefärbt. Bauchschilder der Arme gelblichgrün. Ein ähnliches Exemplar dürfte jedenfalls Delle Chiaje's Beschreibung von Asterias pentagona zu Grunde liegen. Die etwas kleineren Exemplare von Sicilien mit ebenfalls, wenn auch weniger ausgesprochen fünfeckiger Scheibe, lassen die oben geschilderte Färbung nicht erkennen, sondern sind auf der ganzen Oberseite, sowie auf der Unterseite der Scheibe graubraun gefärbt, während die Bauchschilder der Arme auch hier gelblich sind. Die Knötchen auf den Armrückenschildern sind bei diesen Exemplaren viel weniger deutlich zu sehen. 
Gruppe 3. - Scheibendurchmesser bis I $3 \mathrm{Mm}$., Armlänge circa $90 \mathrm{Mm}$. Scheibe kreisrund und auf der Oberseite mit kurzen, mehrspitzig endenden Cylinderchen besetzt, zwischen denen, nicht sehr dicht gestellt, $3 \mathrm{Mm}$. lange, zarte Stacheln stehen. Die Radialschilder mit Ausnahme des kurzen, ober dem Armursprung liegenden, einige Granulationen tragenden Fortsatzes ganz nackt. Rückenschilder der Arme meist deutlich gekielt und oft mit Andeutungen eines Knötchens versehen. Armstacheln sehr lang (bis $5 \mathrm{Mm}$.) mit oft mehr als 20 Dörnchen jederseits. Bauchseite der Scheibe meist mit längeren, entweder einspitzig endenden oder in $2-3$ sehr zarte Spitzen auslaufenden Cylinderchen besetzt.

Die Exemplare von Zara zeichnen sich dadurch aus, dass die Cylinderchen auf der Scheibenoberseite ziemlich dick und kurz sind und in 2-6 Dörnchen auslaufen (23, pl. II, Fig. I 5, г6, I 7). Die Färbung der Thiere ist gelblich bis graulichweiss, die Radialschilder sind oft etwas dunkler gefärbt. Die Arm- und Scheibenstacheln, sowie die Cylinderchen sind gelblichweiss. Durch besonders feine, haarartige Armstacheln, sowie durch schlankere, meist dreispitzig endende Cylinderchen auf der Scheibenoberseite sind viele Exemplare aus Pola gekennzeichnet, dieselben sind fast rein weiss und haben röthliche Binden über die Arme.

Weitere, etwas kleinere Exemplare dieser Varietät sind von Lesina vorhanden, auch diese haben zum Theil äusserst zarte Armstacheln.

Es scheint mir sicher, dass die von Sars beschriebene Ophiothrix fragilis var. tenuispina mit dieser Varietät zusammenfällt.

Gruppe 4. - Scheibendurchmesser 7 Mm., Armlänge 5o Mm. Scheibe oben von ziemlich langgestreckten, meist dreispitzig endenden Cylinderchen (23, pl. II, Fig. 40) bedeckt, zwischen denen mehr oder weniger feine, lange Stacheln stehen. Die Radialschilder sind nicht mehr vollständig nackt, sondern tragen einige sehr zarte, ebenfalls meist dreispitzig endende Cylinderchen. Die Knötchen auf den Armrückenschildern meist sehr deutlich ausgebildet. Armstacheln ziemlich kurz (2-2.5 Mm.), mit höchstens I 5 Dörnchen jederseits. Die Scheibenunterseite trägt fast ausschliesslich zarte Stacheln.

Die vorliegenden Exemplare stammen von Lussin und zeigen eine graulichweisse bis röthliche Färbung.

Gruppe 5, Fig. 38. - Diese Gruppe ist von der früheren, sowie von der nächstfolgenden nicht scharf abgegrenzt, sie umfasst solche Formen, deren Scheibe sowohl auf der Ober-wie auf der Unterseite zum grössten Theil mit mehrspitzig endenden Cylinderchen besetzt ist und nebstdem auf der Oberseite noch einige wenige Stacheln trägt. Auf den Radialschildern stehen meist ebenfalls einige zarte Cylinderchen. Die Armstacheln sind gewöhnlich ziemlich kurz, die Knötchen auf den Armrückenschildern zuweilen deutlich sichtbar, oft aber auch kaum angedeutet.

Hieher gehören einige bläulichgrau gefärbte, ziemlich kleine Thiere von Zara, deren kleinstes einen Scheibendurchmesser von nur $3 \mathrm{Mm}$. hat; dieses ist mit sehr wenigen Cylinderchen und Stacheln bekleidet, so dass die Scheibenbeschilderung deutlich sichtbar ist.

Weiters dürften mehrere äusserst zartstachelige Formen von Rovigno, die durch grünliche oder rosenrothe Färbung mit schönen, dunkelbraunen Zeichnungen auf Scheiben- und Armoberseite auffallen, hieher zu zählen sein. Eines der vorliegenden Exemplare ist durch einen sehr breiten, weissen Strich in der Mittellinie der Armoberseite ausgezeichnet. 
Schliesslich reihen sich hier die theils grünlich, theils röthlich oder bräunlich gefärbten, zahlreichen Exemplare von Lesina an. Einzelne von ihnen erreichen eine nicht unbedeutende Grösse (Scheibendurchmesser $9 \mathrm{Mm}$., Armlänge $55 \mathrm{Mm}$.). Nicht selten findet sich am Scheibenrücken ein grosses, entweder heller oder dunkler als die übrige Scheibenoberfläche gefärbtes Fünfeck. (Bezüglich einiger Exemplare von Zaule vgl. Gruppe 6.)

Als Uebergangsglied dieser Gruppe zur nächsten seien hier noch die Exemplare von Neapel genannt, deren Scheibe mit meist dreispitzig endenden Cylinderchen bedeckt ist, zwischen denen einzelne Cylinderchen stehen, welche Tendenz zur Stachelbildung (23, pl. II, Fig. 5, 7; pl. III, Fig. 20) zeigen. Die Radialschilder sind ganz nackt. Die Färbung ist oben bläulichgrün, die Bauchschilder der Arme sind besonders nach innen zu heller.

Gruppe 6, Fig. 39. - Meist kleinere Exemplare, bei denen die Scheibe ausschliesslich von sehr zarten, mehrspitzigen Cylinderchen besetzt ist. Die Radialschilder tragen meist einige, ähnliche Cylinderchen. Die Knötchen auf den Armrückenschildern sind zuweilen ziemlich deutlich ausgebildet. Die Armstacheln sind äusserst zart und ziemlich kurz und tragen nie mehr als i 4 Dörnchen jederseits.

Hieher sind theils röthlich, theils grünlich gefärbte Exemplare von Rovigno, graubraun gefärbte von Pola und rosenrothe vom Cap bon (Nordküste von Afrika) zu zählen; ein Exemplar von Rovigno ist durch einen hellen Streifen längs des Armrückens ausgezeichnet. Speciell unter den zahlreich vorhandenen Exemplaren von letzterem Fundorte finden sich zahlreiche Uebergangsglieder zu der früheren Gruppe. Besonders auffallend sowohl durch seine Färbung, indem das grünlich gefärbte Thier auf seiner Scheibenoberfläche ein sehr grosses, lebhaft roth gefärbtes Fünfeck trägt, als auch durch den ziemlich dichten Besatz der Radialschilder mit Cylinderchen ist ein von Herrn Dr. von Marenzeller bei Zaule zwischen Algen gefundenes Exemplar. Es hat einen Scheibendurchmesser von $4.5 \mathrm{Mm}$., eine Armlänge von circa $35 \mathrm{Mm}$. Die Knötchen auf den Armrückenschildern sind ungemein gut ausgebildet. Mehrere andere am selben Fundorte gesammelte, noch etwas kleinere Exemplare entbehren der charakteristischen Färbung der Scheibenoberseite, zeichnen sich aber durch den Besitz einiger weniger Stacheln aus, weshalb sie auch zur vorherigen Gruppe gestellt werden könnten. Es zeigt sich somit hier, sowie bei den oben erwähnten Exemplaren von Rovigno besonders deutlich, dass die Art der Bedeckung der Scheibe mit Cylinderchen oder mit Stacheln kein Merkmal ist, welches hervorragenden Werth für die Systematik hat.

Zaule (Bai von Muggia), Rovigno, Pola, von Marenzeller; Lussin; Zara, von Frauenfeld; Lesina, von Marenzeller; Sicilien; Neapel (zoologische Station); Cap bon, Bobrik.

\section{Ophiothrix angulata Say.}

1825. Ophiura angulata Say. (4), pag. 145. - 1882. (29) pag. 219.

Die beiden von dem Museum of Comp. Zoolog. zu Cambridge erhaltenen Exemplare unterscheiden sich bei sonstiger vollkommener Uebereinstimmung sehr durch verschiedene Stachelbekleidung der Scheibe (vgl. I7, pag. I63-I64); während nämlich das eine nur kurze, dreispitzig endende Stümpfchen aufweist, besitzt das andere neben diesen sehr zahlreiche, sechsmal so lange, dornige Stacheln. Die als Ophiothrix Kröyeri Ltk. bestimmt gewesenen Exemplare von Rio Janeiro schliessen sich in Hinsicht der Scheibenbestachelung an das zweite, die Exemplare von den übrigen Fundorten an das erste der oberwähnten Thiere an. Hinsichtlich der Färbung will ich nur hervorheben, 
dass alle Exemplare, mit Ausnahme der von Porto Prince und von Westafrika, einen deutlichen, lichten Streifen in der Medianlinie des Armrückens haben, die letztgenannten Exemplare besitzen am aboralen Rande der Arm-Rückenschilder drei weisse Flecken. Die Arme des Exemplars von Porto Prince sind auf der Oberseite schön roth gefärbt.

Charleston (Ca mbridger Museu m); Rio Janeiro (Originalexemplar von Müller und Troschel's Ophiothrix violacea); Porto Prince (Haïti), Bobrik; $0^{*} 7^{\circ} \mathrm{n}$. Br., 23 bis $25^{\circ}$ w. L. (Schilling).

\section{Ophiothrix koreana Dunc.}

I878. (25) pag. 473, pl. XI, Fig. 28-32. - i882. (29) pag. 226.

Die vier von dieser Species vorhandenen, grossen Exemplare (Scheibendurchmesser 8 Mm., Armlänge $44 \mathrm{Mm}$.) stimmen mit Duncan's Speciesbeschreibung gut überein, speciell der charakteristische Knoten am aboralen Ende der Arm-Rückenschilder ist sehr deutlich ausgebildet.

Die Färbung von drei Exemplaren (in Alkohol) ist auf der Scheiben-Ober- und Unterseite braun; die Stacheln sind gelblichweiss. Radialschilder auf der an den Interbrachialraum grenzenden Seite dunkelbraun, sonst gelblichweiss. Rückenschilder der Arme braun, mit einem lichteren Streifen längs der Mittellinie. Bauchschilder der Arme gelblichweiss. Das vierte Exemplar ist lichter gefärbt.

Molukken.

\section{Ophiothrix caespitosa Lym.}

I879. (26) pag. 53, pl. XV, Fig. 4I7-420. - I882. (29) pag. 2I8, pl. XXVI, Fig. I2-I4.

Von den vorliegenden vier Exemplaren dieser Species stimmt nur eines, und zwar das kleinste (Scheibendurchmesser $5 \mathrm{Mm}$., Armlänge $25 \mathrm{Mm}$.) mit Lyman's Beschreibung vollständig überein, bei allen übrigen treten zu den kurzen Stacheln auf der Scheibenoberseite noch längere hinzu, von welchen auch mehrere auf der Scheibenmitte stehen, doch dürfte diesem Unterschiede (vgl. das entsprechende bei Ophiothrix alopecurus M.-Tr.) kein besonderer Werth beizumessen sein. Die Rückenschilder der Arme zeigen einen kleinen Kiel und zuweilen ein kleines Knötchen auf der aboralen Seite. Zahnpapillen sind i 6 - I 8 vorhanden. Das grösste Exemplar hat einen Scheibendurchmesser von $9 \mathrm{Mm}$. und eine Armlänge von circa 45-5o Mm. Färbung des Thieres grünlich bis bräunlich, die Arm-Rückenplatten meist mit helleren aboralen Rändern. Die Arme bei zwei Exemplaren röthlich gebändert.

Von Ophiothrix spiculata Le Conte, mit der diese Form, sehr viel Aehnlichkeit hat, unterscheidet sie sich besonders durch andere Form der Arm-Bauchschilder.

Sidney, Dr. A. Wolf.

\section{Ophiothrix propinqua Lym.}

I86I. (I5) pag. 83. - I882. (29) pag. 220.

Hinsichtlich des Unterschiedes dieser Form von Ophiothrix Martensi Lym., der sie sehr nahe steht, wäre zu bemerken, dass hier die Armstacheln bis an ihre Basis gezähnt sind und dass dieselben oft an ihrem Ende ein grösseres, aboral gerichtetes Dörnchen tragen. Auch die Gestalt der Arm-Rückenplatten, sowie die für Ophiothrix Martensi charakteristische Farbenzeichnung derselben unterscheidet, abgesehen von anderen Merkmalen, diese beiden Species zur Genüge.

Tor (Rothes Meer), von Frauenfeld; Banda-Inseln, Torresstrasse, Dr. A. Wolf. 


\section{Ophiothrix nereidina Lmk.}

I8I6. Ophiura nereidina Lmk. (3), pag. 554. - 1870. Ophiothrix cataphracta v. Mart. (21), pag. 259. - 1882. (29), pag. $22 \mathrm{I}$.

Der Hauptunterschied dieser Form von der von v. Martens beschriebenen Ophiothrix cataphracta scheint mir nur im Vorhandensein, respective Fehlen von Granula auf der Scheibenoberseite zu liegen, weil aber das eine der mir aus Singapore vorliegenden Exemplare einige, wenn auch nicht zahlreiche Granula auf den die Radialschilder trennenden Schildchen trägt, ja sogar das eine oder andere derselben auf den Radialschildern selbst aufsitzt, hingegen das zweite, sonst congruente Exemplar auf seiner Scheibenoberseite ganz nackt ist; so glaube ich annehmen zu sollen, dass die Ophiothrix cataphracta v. Mart. nur eine Varietät der Ophiothrix nereidina ist.

Das Exemplar von den Nikobaren, welches ebenfalls sonst in jeder Beziehung, auch in der Färbung, mit den beiden obigen Exemplaren übereinstimmt, trägt auch in der Scheibenmitte keine Stacheln, sondern nur rundliche Schilder.

Nikobar-Inseln, Novara-Expedition; Singapore, Baron R ansonnet; Amboina, Dr. Doleschal.

\section{Ophiothrix galateae Lütk.}

1872. (22) pag. 90 und 108. - 1882. (29) pag. 227.

Diese Species steht der Ophiothrix hirsuta var. punctolimbata (s. pag. 3 I 2 ) nahe, unterscheidet sich aber von dieser durch vollkommen nackte Radialschilder. Da die mir vorliegenden Exemplare in einigen, wenn auch nur minder wichtigen Punkten von Lütken's Charakteristik dieser Species abweichen, lasse ich eine kurze Beschreibung dieser Exemplare folgen:

Scheibendurchmesser $14 \mathrm{Mm}$., Arme mehr als zehnmal länger als der Scheibendurchmesser. Scheibenoberseite mit Ausnahme der Radialschilder dicht mit ein- bis mehrspitzig endenden, kurzen Cylinderchen besetzt. Radialschilder dreieckig, nackt, mit einem kurzen, über der Armbasis liegenden, einige heller gefärbte Granulationen tragenden Fortsatz versehen. Die Länge der Radialschilder verhält sich zum Durchmesser der Scheibe wie I : $3 \cdot 2$. Rückenschilder der Arme doppelt so breit als lang, der aborale Rand convex, viel länger als der orale, die Seitenränder gerade, die Schilder sind somit ähnlich den auf Taf. XIII, Fig. 35, abgebildeten. 5-6 Armstacheln, der zweite von oben am längsten, und zwar so lang als circa vier Rückenschilder der Arme. Bauchseite der Scheibe von meist ein- bis dreispitzig endenden Cylinderchen ziemlich dicht besetzt. Mundschilder fast doppelt so breit als lang, aussen convex, nach innen einen stumpfen Winkel bildend und in Verbindung mit Genitalschuppen stehend. Seitenmundschilder ziemlich gross. Die Zahnpapillen stehen auf einer breiten, hufeisenförmigen Fläche; es sind circa I 4 vorhanden, hievon stehen meist zehn an der Peripherie und vier innerhalb. Bauchschilder der Arme quadratisch, die Seitenkanten convex. Eine kleine rundliche Tentakelschuppe.

Färbung der Scheibenoberseite bläulichgrau, auf den Radialschildern einige dunkelblaue Punkte. In der Mittellinie des Armrückens eine vielfach unterbrochene, d. h. in einzelne weisse Punkte aufgelöste, hellere Linie. Bauchseite der Scheibe hell-bläulich bis grau. Bauchschilder der Arme weiss, längs der Mittellinie der Armunterseite meist ein breites, violettes Band. Arme dunkler blau gebändert.

Das Exemplar von den Nikobaren ist sehr jung, stimmt aber in jeder Beziehung vollkommen mit dem Exemplare von der Insel Réunion überein; es hat einen Scheibendurchmesser von $4 \mathrm{Mm}$. bei einer Armlänge von circa 3o Mm.

Insel Réunion, Dr. Körbl; Nikobar-Inseln, Novara-Expedition; Cebu, Dr. Körbl. 


\section{Ophiothrix stelligera Lym.}

I874. (23) 237, pl. III, Fig. 15-20. - I882. (29) pag. 220.

Wenngleich nicht alle vorhandenen Exemplare vollkommen mit Lyman's Beschreibung übereinstimmen, dürften diese doch nur als Varietäten obiger Species zu betrachten sein. Während die Scheibenoberseite bei einer Gruppe von Exemplaren nur von kurzen, fünf- bis achtspitzig endenden Cylinderchen bedeckt ist und höchstens in der Mitte einige, etwas längere, stachelartige Gebilde trägt, ist der Scheibenrücken einer zweiten Gruppe mit zarteren, zwei- bis dreispitzig endenden Cylinderchen bedeckt, ähnlich wie dies Lyman für Ophiothrix exigua beschreibt; hingegen ist die Scheibenunterseite bei allen Exemplaren mehr weniger dicht mit ähnlichen Gebilden bekleidet, wie sie auf dem Scheibenrücken des betreffenden Exemplares stehen, und dies ist vcr Allem der Grund, warum ich (vgl. 23, pag. 237) alle betreffenden Exemplare zu Ophiothrix stelligera rechne. Die Rückenschilder der Arme sind bei der zweiten Gruppe fächerförmig, während die der ersten Gruppe wohl ähnlich gestaltet sind, aber meist gegen das adorale Ende nicht so stark convergirende Kanten besitzen.

Die Färbung der Thiere der ersten Gruppe ist oben etwas grünlich, zuweilen mit einer helleren, von zwei dunkleren Streifen umsäumten Linie längs des Armrückens. Die Thiere der zweiten Gruppe sind meist fleischfarben oder röthlich, mit einer ähnlichen Zeichnung auf dem Armrücken. Bei manchen Exemplaren der zweiten Gruppe ist die Scheibenunterseite in den Interbrachialräumen sehr dunkel gefärbt.

Japan, Dr. von Roretz, Dr. Körbl.

\section{Ophiothrix demessa Lym.}

I86I. (I5) pag. 82. - I882. (29) pag. 226.

Die vorliegenden, im Aeusseren der Ophiothrix hirsuta und Ophiothrix longipeda sehr nahestehenden Exemplare dürften obiger Species angehören, da ihre ArmRückenschilder sehr auffallende Knötchen, zuweilen kurze, stachelförmige Granulationen tragen. Aehnliche, aber nicht so auffallende Granulationen besitzen allerdings auch einzelne Exemplare von Ophiothrix hirsuta M.-Tr. Die Scheibe wird oben und unten von kurzen, kräftigen, vier- bis sechsspitzig endenden Dörnchen bedeckt, welche auf den Radialschildern weniger dicht gestellt sind.

Scheibendurchmesser des grössten Exemplares I7 Mm., Armlänge circa $20 \mathrm{Cm}$. (Verh. г: I2). Bei einem jüngeren Thiere von $7 \mathrm{Mm}$. Scheibendurchmesser ist dies Verhältniss etwa ı: го. Rückenschilder der Arme viereckig, aussen breiter als innen, der aborale Rand convex (Taf. XIII, Fig. 28). Elf zarte, glasige Armstacheln, die obersten zwei meist kürzer, die nächsten 3-4 am längsten, der unterste, besonders gegen das Ende des Armes zu oft hakenartig. Mundschilder circa anderthalbmal so breit als lang, in der Mitte vertieft und in Verbindung mit zwei ansehnlichen Genitalschuppen. Untere Armplatten wenig länger als breit, abgerundet. Tentakelschuppen mässig gross, bei einzelnen Exemplaren zugespitzt, bei anderen mehr abgerundet.

Färbung der Scheibe gelblich, die der Armoberseite bläulich, zuweilen mit helleren Zeichnungen; meist eine dunkle Bänderung der Armoberseite sichtbar. Ein kleines Exemplar von den Banda-Inseln mit einem Scheibendurchmesser von 5.5 Mm. bei einer Armlänge von circa $40 \mathrm{Mm}$. dürfte wegen des Besatzes der Armrückenschilder mit kleinen Stacheln auch hieher zu zählen sein; es unterscheidet sich von den übrigen Exemplaren durch verhältnissmässig kürzere Arme, durch meist dreispitzig endende Cylinderchen als Scheibenbedeckung und eine mehr zugespitzte Tentakelschuppe.

Dschidda, Dr. Billitzer; Banda-Inseln, Dr. A. Wolf. 


\section{Ophiothrix hirsuta M.-Tr.}

I842. (6) pag. III. - i882. (29) pag. 226.

Da die Aehnlichkeit, insbesondere in Hinsicht der Scheibe, zwischen dieser Species und der Ophiothrix longipeda Lmk. sehr gross ist und andererseits obige Species ziemlich bedeutend variirt, so dürfte es am Platze sein, die Merkmale dieser Species mit speciellem Hinblick auf Ophiothrix longipeda (vergl. 29, pag. 2 I 4 ) genau zu beschreiben.

Scheibendurchmesser bis $20 \mathrm{Mm}$., Armlänge 9- I 3 mal grösser als der Scheibendurchmesser. Scheibe oben dicht mit kleinen, meist mehrere feine Spitzen tragenden, cylindrischen Granula besetzt. Radialschilder gross, dreieckig, mit einem Fortsatz nach aussen zu und länger als die von Ophiothrix longipeda. Das Verhältniss zwischen Scheibendurchmesser und der Länge der Radialschilder ist hier 2.7 : 1 , während es bei Ophiothrix longipeda 3·6: I ist. Die Radialschilder sind weit weniger dicht als die Scheibe mit Granulationen bedeckt, letztere sind hier meist nur kugelige, auf ihrer Oberfläche rauhe Körnchen. Die Radialschilder eines Paares berühren sich nicht, sondern sind durch einen schmalen, mit cylindrischen Granula (s. oben) bedeckten Streifen getrennt. Die Rückenschilder der Arme sind wenigstens am Anfange des Armes oval (Taf. XIII, Fig. 34) und haben keine für Ophiothrix longipeda charakteristische, von den aboralen und den Seitenkanten gebildete, spitze Winkel (Taf. XIII, Fig. 27). Ferner sind die Rückenschilder der Arme hier stets, zuweilen sogar sehr stark granulirt, während sie bei Ophiothrix longipeda meist nackt, zuweilen jedoch auch etwas granulirt sind. Armstacheln gewöhnlich 6-9, sehr selten, wie dies Müller und Troschel angeben, ı ; die längsten Stacheln (der zweite, dritte und vierte von oben) circa 3 1/2 mal so lang als eine Arm-Bauchplatte. Die Stacheln sind hier meist etwas weiter gegen ihre Basis zu mit Dörnchen versehen, als dies bei Ophiothrix longipeda der Fall ist; bei letzterer Form werden die Stacheln gegen ihr Ende zu etwas breiter. Der unterste Stachel zeigt gegen die Armspitze zu Neigung zur Hakenbildung. Interbrachialräume der Scheibenunterseite theils mit denselben Cylinderchen, welche auf der Oberseite stehen, theils, und zwar besonders gegen die Mundschilder zu mit kurzen, einspitzig endenden Stacheln besetzt; bei Ophiothrix longipeda stehen hingegen, mit Ausnahme des äussersten Randes auf der Bauchseite der Scheibe, einspitzige, kurze, konische Stacheln. Mundschilder breiter als lang, nach aussen convex, nach innen zu einen Winkel bildend, sie stehen in Verbindung mit kleinen Genitalschuppen. Seitenmundschilder ziemlich klein. Meist circa $26-28$ dicht gedrängte Zahnpapillen vorhanden. Vier Zähne. Bauchschilder der Arme etwas breiter als lang, viereckig, mit convexen Seitenkanten, oder fast sechseckig. Tentakelschuppe klein, oval.

Die Färbung ist eine heller oder dunkler violette, die Scheibenoberseite sowie die Radialschilder sind oft mit dunkelblauen Punkten oder Zeichnungen geziert. Die Arme sind oft dunkler, zuweilen röthlich gebändert, besonders schön ist manchmal die Oberfläche der Arm-Rückenschilder gezeichnet, oft sind letztere obendrein weiss gesäumt. Die Bauchseite der Arme ist oft dunkelviolett wie die Oberseite, mitunter aber heller, ja selbst fleischfarben; ein Exemplar von Java zeigt diese Färbung auch auf der Scheibe, die Arme desselben sind oben und unten roth gebändert.

Varietät (Taf. XIII, Fig. 35): Als solche dürften zwei Exemplare von Cebu und ein Exemplar von den Viti-Inseln zu betrachten sein. Diese Varietät unterscheidet sich von der typischen Ophiothrix hirsuta durch folgende Merkmale:

Die Radialschilder sind an der dem benachbarten Schilde desselben Paares zugekehrten Seite etwas concav, auch stehen sie etwas mehr getrennt. Die Rückenschilder der Arme sind sehr breit und oft fast sechseckig, ihr aboraler Rand viel länger als der 
orale; sie erinnern durch den ziemlich ausgeprägten Winkel an den aboralen Ecken an die Rückenschilder von Ophiothrix longipeda. Neun Armstacheln, die in Hinsicht ihrer Bedornung denen von Ophiothrix hirsuta ähnlich sind, sich aber dadurch, dass sie gegen ihr Ende zu nicht an Breite abnehmen, an die von Ophiothrix longipeda anschliessen. Bauchschilder der Arme elliptisch, breiter als lang.

Färbung blau, die Rücken- und Bauchschilder der Arme mit dunkelblauen Punkten, besonders an den Rändern gezeichnet.

Diesen Exemplaren sehr ähnlich, namentlich durch die Form der Arm-Rückenschilder, ist ein Exemplar von den Nikobaren, dieses zeigt die dunkle Punktirung letztgenannter Schilder besonders deutlich.

Während die eben erwähnte Varietät sich schon sehr der von v. Martens (2 I, pag. 257 ) beschriebenen Ophiothrix punctolimbata nähert, stimmt ein mir von Singapore vorliegendes Exemplar mit v. Martens Beschreibung völlig überein, höchstens mit Ausnahme dessen, dass neben den Granulationen auch mehrspitzig endende Cylinderchen auf der Scheibenoberseite stehen. Nachdem diese Form, wie wir sahen, durch Zwischenglieder mit Ophiothrix hirsuta verbunden und von der typischen Form der letzteren überhaupt nicht allzu verschieden ist, glaube ich mich zu der Annahme berechtigt, dass wir es hier nicht mit einer neuen Species, sondern nur mit einer Varietät der Ophiothrix hirsuta zu thun haben, die sodann als var. punctolimbata v. Mart. zu bezeichnen wäre.

Tor (Rothes Meer), von Frauenfeld; Nikobar-Inseln, Novara-Expedition; Singapore; Java, J. Pfeiffer; Cebu, Dr. Körbl; Viti-Inseln; Dr. A. Wolf.

\section{Ophiothrix comata M.-Tr. Taf. XIII, Fig. 29-3I.}

I842. (6) pag. II2. - I882. (29) pag. 228.

Da diese Species seit Müller und Troschel nicht aufgefunden und genauer beschrieben wurde, möge hier nach dem Originalexemplare eine genaue Beschreibung derselben Platz finden.

Scheibendurchmesser 3.5 Mm., Armlänge circa $2^{1 / 2}-3 \mathrm{Cm}$. Scheibe oben mit I-3 spitzig endenden, sehr zarten, kurzen Stümpfchen bedeckt, zwischen denen haarförmig dünne, lange Stacheln zerstreut stehen. Die Radialschilder sind dreieckig, von der halben Länge des Scheibendurchmessers und besonders gegen innen zu ebenfalls mit oben geschilderten Stümpfchen besetzt. Die zwei Radialschilder eines Paares berühren sich untereinander nicht ganz, meist entspringen zwischen ihnen mehrere lange Stacheln. Rückenschilder der Arme fächerförmig und zuweilen auf ihrer Oberfläche einige äusserst zarte Dörnchen tragend. 5-6 zarte, dornige Armstacheln, die so lang sind als 5-6 Armglieder, der unterste ist oft zu einem Haken ausgebildet. Bauchseite der Scheibe nur mit sehr kurzen, meist einspitzig endenden Dörnchen besetzt. Die doppelt so breiten als langen Mundschilder stehen in Verbindung mit zwei kleinen Genitalschuppen. Seitenmundschilder verhältnissmässig gross, dreieckig. Von den wie gewöhnlich auf einer verticalen, ovalen Fläche stehenden Zahnpapillen stehen an der Peripherie derselben meist I I- I3, innerhalb 3-5. Die Bauchschilder der Arme sind quadratisch mit etwas concavem aboralen Rande; meist ist in der Mitte derselben eine kleine, manchmal kaum sichtbare, kreisförmige Erhöhung zu sehen, um die sich eine schwache Depression der Bauchschilder herumzieht. Tentakelschuppe sehr klein und spitzig. Färbung des Thieres röthlich; in der Medianlinie des Armrückens verläuft ein heller, rechts und links von zwei dunklen Streifen umsäumter Strich. 
Die übrigen Exemplare erreichen oft eine bedeutendere Grösse, ein Exemplar aus dem Rothen Meere hat einen Scheibendurchmesser von $7 \mathrm{Mm}$. und eine Armlänge von $50 \mathrm{Mm}$. Die Färbung ist auf der Oberseite meist bläulich mit einem hellen, jederseits von einem sehr dunkelblauen Streifen umsäumten Striche auf der Arm-Rückenseite; die Stacheln sind ebenfalls bläulich. Ein Exemplar von Dschidda zeigt keine deutliche Streifung des Armrückens, sondern nur hellere und dunklere Zeichnungen. Das eigenthümliche, oben beschriebene Merkmal der Arm-Bauchplatten ist bei den meisten Exemplaren deutlich zu sehen.

Varietät (Taf. XIII, Fig. 3i): Ein Exemplar von den Nikobaren zeigt bei sonstiger grosser Uebereinstimmung mit obiger Species eine gänzlich andere Bekleidung der Scheibenoberseite. Diese besteht nämlich hier aus grossen Schildern, von denen auch eine Reihe langgestreckter zwischen den Radialschildern liegt. Der Besatz mit Stacheln und dreispitzigen Dörnchen ist sehr spärlich, indem auf jedem Schilde kaum mehr als ein solches Gebilde aufsitzt.

Tor, von Frauenfeld; Rothes Meer; Nikobar-Inseln, Novara-Expedition; Cebu, Dr. Körbl. Originalexemplar von unbekanntem Fundorte.

\section{Ophiothrix foveolata n. sp. Taf. XIII, Fig. 32 und 33.}

Scheibendurchmesser 5.5 Mm., Armlänge circa I7-20 Mm. Scheibe oben mit grossen Schildern bekleidet, welche ziemlich lange, aber nicht sehr zahlreiche, spitz zulaufende, in grubige Vertiefungen der Schilder eingelenkte Stacheln tragen. Dreispitzige Cylinderchen fehlen auf der Scheibenoberseite vollständig, wodurch sich dieselbe, sowie auch durch die andere Form der Scheibenstacheln von der ihr ähnlichen Scheibenoberseite der oben beschriebenen Varietät von Ophiothrix comata unterscheidet. Radialschilder gross, dreieckig, nackt und ziemlich breit. Die beiden Radialschilder eines Paares stossen aussen fast zusammen, gegen innen zu werden sie durch $\mathrm{I}-3$ schmale, lange Schilder getrennt. Zwischen den benachbarten Paaren von Radialschildern befinden sich 3 bis 4 Reihen von Schildern. Rückenschilder der Arme fast ebenso lang als breit, der aborale Rand convex und doppelt so lang als der orale. Sechs ziemlich glatte, an ihrer Basis angeschwollene Armstacheln, der zweite (von oben gezählt) am längsten, die längeren Armstacheln fast nur gegen das Ende zu mit feinen Dornen versehen, der unterste hat meist die Form eines Hakens. Scheibenunterseite mit nach innen zu an Grösse abnehmenden Stacheln bekleidet. Mundschilder doppelt so breit als lang, mit einem kurzen Fortsatz nach innen und in Verbindung mit Genitalschuppen stehend. Seitenmundschilder sehr schmal. Bauchschilder der Arme viereckig, etwas breiter als lang. Auffallend grosse Genitalplatten vorhanden. Eine kleine, feinspitzig endende Tentakelschuppe. Färbung des Thieres bläulichgrau, Stacheln gelblich, Arme etwas dunkler gebändert. Einzelne Schilder auf der Ober- und Unterseite des Thieres dunkelblau gesprenkelt.

Arru-Inseln, Dr. A. Wolf.

\section{Ophiothela Danae Verrill.}

1869. (19) pag. 391. - I882. (29) pag. 230.

Die vorliegenden Exemplare sind von Ophiothela Danae durch kürzere Arme und nicht vollständig aneinanderstossende Radialschilderpaare verschieden. Doch möchte ich sie nicht als neue Species, sondern nur als eine locale Varietät der obigen betrachten, da sie, wie aus der unten folgenden Beschreibung dieser Thiere hervorgeht, in vielen Punkten eine sehr grosse Uebereinstimmung mit Verrill's Charakteristik seiner Ophiothela Danae zeigen. 
Scheibendurchmesser 3.5 Mm., Armlänge I2 Mm. Sechs Arme. Rückenseite der Scheibe von grossen, bis nahe an den Scheibenmittelpunkt reichenden Radialschildern bekleidet, welche auf ihrer Oberfläche grosse, warzige, aber nicht sehr dicht gestellte Granulationen tragen. Die Radialschilder eines Paares berühren sich der ganzen Länge nach; die der benachbarten Paare lassen zwischen sich einen schmalen, nach aussen zu breiter werdenden, ebenso wie die Scheibenmitte dicht mit sehr grossen, stumpf kegelförmigen Granulationen bedeckten Streifen frei. Die Rüickenschilder der Arme sind von sehr dicht gestellten, grossen, warzigen Granulationen bedeckt. Mundschilder queroval, breiter als lang und ebenso wie die Seitenmundschilder nicht sehr deutlich contourirt, da sie von einer feinen Haut überzogen zu sein scheinen. Zahlreiche, ähnlich wie bei Ophiothrix gestellte Zahnpapillen. Die Seitenarmplatten springen weit vor und tragen vier mit feinen Dörnchen versehene, kurze Stacheln, die Dörnchen des untersten, kleineren Armstachels sind meist auffallend gross und gekrümmt, so dass dieser die Form eines mehrspitzigen Hakens annimmt. Die Bauchplatten der Arme sind trapezförmig, längs der Mittellinie des Armes zeigen sie eine Furchung, rechts und links davon sind sie etwas aufgetrieben.

Färbung oben meist dunkelblau mit weissen Zeichnungen, die Granula sind oft hell gefärbt, einzelne Exemplare röthlich mit blauen Zeichnungen. Scheibenunterseite ähnlich gefärbt wie die Oberseite. Beschilderung der Bauchseite des Thieres meist gelblichweiss.

Die Thiere sitzen in ziemlich grosser Zahl auf einem Exemplar von Suberogorgia suberosa Pall. aus Singapore auf.

\section{Ophiolophus n. gen.}

Scheibe sammt den Radialschildern von einer Haut bekleidet. Die Radialschilder besitzen eine schmale Basis, auf welcher sich eine, gegen den Scheibenrand zu allmälig ansteigende und ober dem aboralen Ende des Schildes vertical abfallende Crista erhebt, welche weit aus der Ebene der Scheibe hervorragt. Mundschilder und Seitenmundschilder, sowie in zwei Reihen gestellte Zahnpapillen, aber keine eigentlichen Zähne, vorhanden. Rückenschilder der Arme zuweilen aus zwei in der Mittellinie des Armrückens zusammenstossenden Theilen bestehend. Die Bauchschilder der Arme sind undeutlich contourirt und von einer dünnen Haut überzogen. Armstacheln vorhanden. Keine Tentakelschuppe.

\section{Ophiolophus Novarae n. sp. Taf. XIII, Fig. 40 und 4I.}

Scheibendurchmesser vom Ursprung eines Armes bis zum gegenüberliegenden Interbrachialraum i $8 \mathrm{Mm}$., Armlänge $70 \mathrm{Mm}$. Die Scheibe ist in den Interbrachialräumen tief eingebuchtet und auf der Ober- wie auf der Unterseite von einer nackten Haut bekleidet, welche auch die Radialschilder umhüllt. Letztere bilden eine Crista, die circa $8 \mathrm{Mm}$. lang ist und sich an ihrem höchsten Punkte $3-3.5 \mathrm{Mm}$. über das Niveau der Scheibe erhebt. Die ersten 2-3 Armrückenschilder tragen meist je einen kräftigen, bis $\mathrm{I}^{\mathrm{I}} / 2 \mathrm{Mm}$. hohen, stumpfen Stachel. Die Arme sind am Ursprung seitlich flach gedrückt, im weiteren Verlaufe sind sie jedoch dorsoventral abgeflacht, an ihren Enden sind sie astrophytonartig eingerollt. Die Rückenschilder der Arme reichen weit nach abwärts, die Seitenarmschilder sind sehr klein und tragen $4-5$ von oben nach unten an Grösse abnehmende, kurze Stacheln. Die Bauchschilder sind gewölbt, aber undeutlich von einander abgesetzt. Die Mundschilder sind ziemlich klein, etwas breiter als lang und etwas unregelmässig geformt, jedes derselben lässt in seiner Mitte eine feine Oeffnung 
erkennen. Die runden Seitenmundschilder liegen nicht, wie gewöhnlich, seitlich der Mundschilder, sondern mehr gegen die Scheibenmitte zu, die beiden Schilder eines Paares berühren sich untereinander. Auf der langgestreckten, von den Mundeckstücken gebildeten verticalen, ovalen Fläche sitzen, in zwei Reihen geordnet, circa acht Zahnpapillen auf.

Färbung des Thieres braunschwarz, nur die Bauchschilder der Arme sind in der Mitte oft gelblichweiss.

Nikobar-Inseln, Novara-Expedition.

\section{Verzeichniss der in Betracht gezogenen Arten.}

\begin{tabular}{|c|c|c|}
\hline & Seite & Seite \\
\hline Amphiu & a brevispina n. sp. & Ophionereis porrecta $\mathrm{Lym}$. \\
\hline , & candida Ljn. . . . . . . . 299 & » reticulata Say. \\
\hline , & Chiajei Forb. . . . . 299 & Ophioplocus imbricatus M.-Tr. . . . . \\
\hline 》 & constricta Lym. . . . . 300 & Ophiothela Danae Verrill. . . . . . . . $3^{1} 3$ \\
\hline » & crassipes Ljn. . . . . . . 299 & Ophiothrix alopecurus M.-Tr. . . . 304, 305 \\
\hline$\gg$ & filiformis O. F. Müll. . . . 300 & , angulata Say. ...... 307 \\
\hline » & glabra Lym. . . . . . 300 & caespitosa Lym. . . . . 308 \\
\hline 》 & Müllerin. sp. ..... 300 & cataphracta v. Mart. . . . 309 \\
\hline$\gg$ & occidentalis Lym. . . . . 300 & comata M.-Tr. . . . 3 312, $3 \mathrm{I} 3$ \\
\hline$»$ & Stimpsoni Lütk. . . . . . . . 299 & demessa Lym. . . . . . . 310 \\
\hline Asterias & ventagona Delle Chiaje . . . . 305 & echinata M.-Tr. . . . 304 \\
\hline Ophiacti & Ljungmani n. sp. . . . . 297 & foveolata n. sp. ...... 313 \\
\hline$\gg$ & Lütkeni n. sp. . . . . . 298 & fragilis Abild. . . . 304, 305 \\
\hline 》 & macrolepidota n. sp. . . 298 & $\gg$ M.-Tr. ... 304, 305 \\
\hline » & Mülleri Lütk. . . . . . 298 & var. tenuispina S. 305,306 \\
\hline 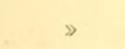 & nama Lym. . . . . . . 297 & galateae Lütk. . . . . . 309 \\
\hline 》 & resiliens Lym. . . . . . 297 & hirsuta M.-Tr. . . 310, 31 I, 312 \\
\hline » & Savignyi M.-Tr. . . . . 296 & koreana Dunc. ..... 308 \\
\hline$»$ & virens Sars. . . . . . 296 296 & longipeda Lmk. . $3 \mathrm{IO}, 31 \mathrm{I}, 3 \mathrm{I} 2$ \\
\hline Ophioco & na brevipes Pet. . . . . . 303 & lusitanica Ljn. ... . . . 304 \\
\hline$»$ & erinaceus M.-Tr. . . . . 302 & Martensi Lym. . . . . 308 \\
\hline 》 & marmorata n. sp. . 303 & nereidina Lmk. . . . . 309 \\
\hline » & Schönleinii M.-Tr. . . 303 & propinqua Lym. . . . . 308 \\
\hline 》 & scolopendrina Lmk. . 302, 303 & punctolimbata v. Mart. ... 312 \\
\hline » & Valenciae M.-Tr. . . . . 303 & quinquemaculata M.-Tr. . . 304 \\
\hline Ophiogly & pha affinis Lütk. . . . . 295 & spiculata Le Conte . . . . 308 \\
\hline ( & albida Forb. . . . 294 & » stelligera $\mathrm{Lym}$. \\
\hline$»$ & Grubii Hell. . . . 294, 295 & Ophiura abyssicola Forb. . . \\
\hline 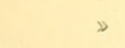 & nodosa Lütk. . . . . 296 & „appressa Say. . . . . . . \\
\hline 》 & robusta Ayr. . . . . . 296 & Tenorii Delle Chiaje . . . . \\
\hline Ophiolep & is cincta M.-Tr. . . . . . . 294 & , teres Lym. . . . . . . . . . 293 \\
\hline$\gg$ & Tenorii M.-Tr. . . . 291, 296 & Pectinura spinosa Ljn. . . . . . . . 293 \\
\hline Ophiolok & hus Novarae n. gen., n. sp. . 3I4 & » stellata Ljn. . . . . . . . 293 \\
\hline Ophione, & hthys phalerata Lym. . . 30I & \\
\hline
\end{tabular}




\section{Erklärung der Tafeln.}

\section{Tafel XII}

Fig. I. Ophioglypha affinis Lütk., Unterseite. Vergr. $1: 7 \cdot 5$.

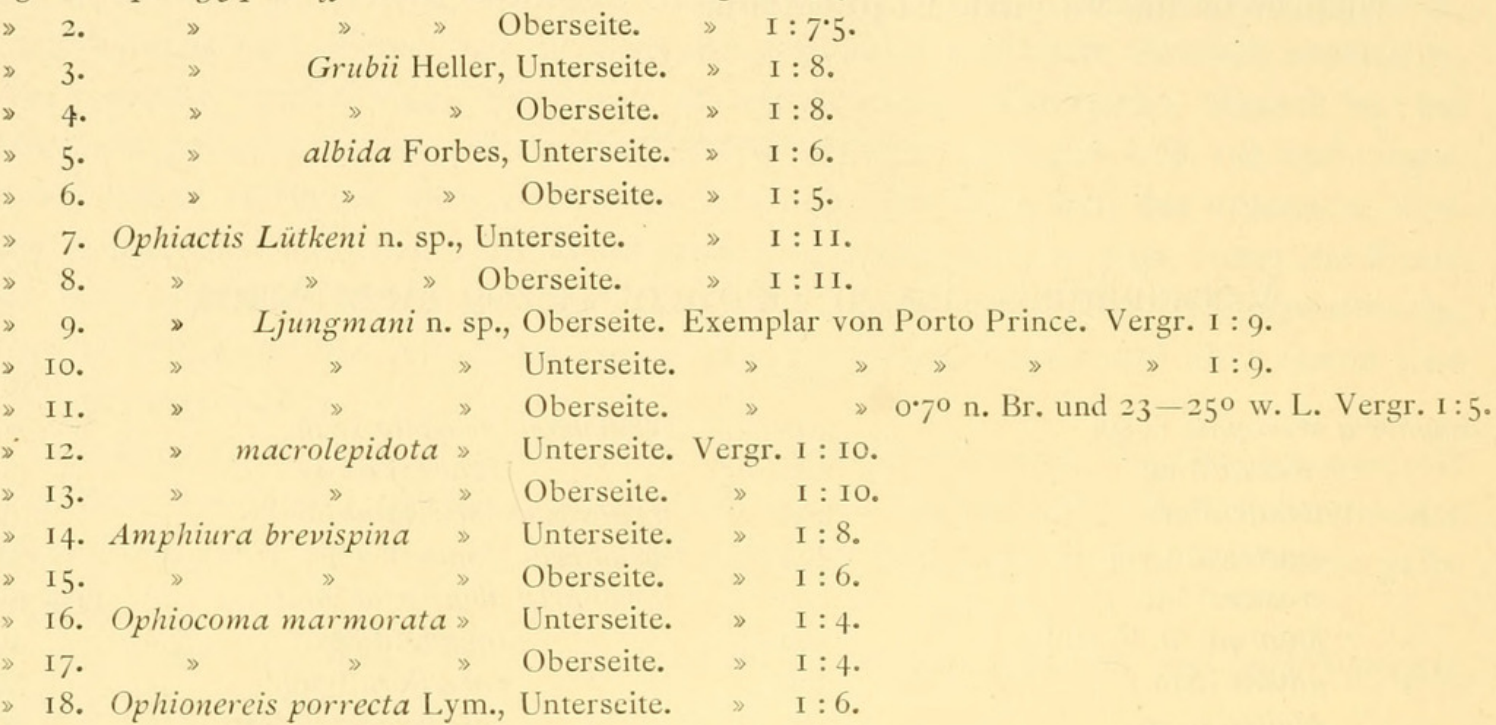

\section{Tafel XIII.}

Fig. 19. Ophiactis resiliens Lym., Unterseite. Vergr. $1: 4$.

20. 》 》 $\gg$ Oberseite. $~ I: 4$.

21. Oberster Armstachel von Ophiocoma scolopendrina Lmk. Exemplar von Dschidda. Vergr. I 2. 22 und 23. Derselbe von Exemplaren aus dem rothen Meere. Vergr. 1 : 5.

24. Derselbe von einem Exemplare von Australien. Vergr. I : 5.

25. Amphiura Mülleri n. sp., Unterseite. Vergr. I : I2.

26. 》 》 Oberseite. $\gg 1: 10$.

27. Armoberseite von Ophiothrix longipeda Lmk. Vergr. $1: 4$.

$28 . 》 \gg$ demessa Lym. $\gg \quad \mathrm{I}: 5$.

29. Ophiothrix comata M.-Tr., Unterseite. Vergr. I : 9.

30. $\gg$ \# Oberseite. $\gg I: 7$.

(Wegen schlechten Erhaltungszustandes des Müller und Troschel'schen Originalexemplars wurde die Aufnahme nicht von diesem, sondern von einem mit demselben vollständig übereinstimmenden Thiere gemacht.)

3I. Ophiothrix comata M.-Tr. (Varietät), Oberseite. Vergr. I $: 8 \cdot 5$.

32. $>$ foveolata n. sp., Unterseite. Vergr. $1: 6 \cdot 5$.

33. $\gg \gg$ Oberseite. $\gg I: 5.5$.

34. Armoberseite von Ophiothrix hirsuta M.-Tr. Vergr. I : 4.

35. $\gg \quad$ einer Varietät von Ophiothrix hirsuta M.-Tr. Vergr. I : 4.

36. Ophiothrix alopecurus M.-Tr. (Exemplar aus der Bai von Muggia), Unterseite. Vergr. I : 3 .

37.

38. $\gg$ ( $\gg$ (Exemplar von Rovigno), Oberseite. Vergr. I : 4 .

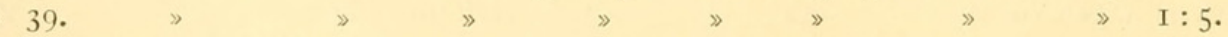

40. Ophilophus Novarae n. gen., n. sp., Unterseite. Vergr. I : 2 .

4 I. $\gg \gg$ Oberseite. $\gg \quad$ I $: 2$. 


\section{$2 \mathrm{BHL}$ Biodiversity Heritage Library}

Marktanner-Turneretscher, Gottlieb. 1887. "Beschreibung neuer Ophiuriden und Bemerkungen zu bekannten." Annalen des K.K. Naturhistorischen Hofmuseums 2, 291-316. https://doi.org/10.5962/bhl.part.29076.

View This Item Online: https://www.biodiversitylibrary.org/item/28439

DOI: https://doi.org/10.5962/bhl.part.29076

Permalink: https://www.biodiversitylibrary.org/partpdf/29076

\section{Holding Institution}

MBLWHOI Library

\section{Sponsored by}

MBLWHOI Library

\section{Copyright \& Reuse}

Copyright Status: NOT_IN_COPYRIGHT

This document was created from content at the Biodiversity Heritage Library, the world's largest open access digital library for biodiversity literature and archives. Visit BHL at https://www.biodiversitylibrary.org. 